\title{
Soft tissue pseudotumours: a pictorial review with emphasis on MRI
}

\author{
Evangelos Perdikakis ${ }^{1}$ \\ Ioannis Tsifountoudis ${ }^{1}$ \\ loannis Kalaitzoglou ${ }^{2}$ \\ Christos Rountas ${ }^{3}$ \\ Nikos Malliaropoulos 4 \\ Nicola Maffulli 5
}

1 Department of Radiology, 424 General Military Hospital, Thessaloniki, Greece

2 Asclepios Diagnostic Center, Thessaloniki, Greece

3 Department of Radiology, University of Thessaly, Larisa, Greece

4 Sports and Exercise Medicine Clinic, Thessaloniki, Greece; Centre for Sports \& Exercise Medicine, Queen Mary, University of London, London, UK

5 Centre for Sports \& Exercise Medicine, Queen Mary, University of London, Barts And The London School of Medicine and Dentistry, Mile end Hospital, London, UK; Department of Physical and Rehabilitation Medicine, University of Salerno, Italy

Corresponding author:

Ioannis Tsifountoudis

Department of Radiology,

424 General Military Hospital

56403 Thessaloniki, Greece

E-mail: tsifjo@gmail.com

\section{Summary}

Background: Several tumour-like conditions of the soft tissues may be encountered in clinical practice, or when patients undergo radiologic examinations. Al-though advances in cross sectional imaging (ultra-sound, MDCT and MRI) play a pivotal role in the correct evaluation of tumour-like lesions, a system-atic approach is needed to achieve a definitive di-agnosis or limit the differential diagnosis. Clinical history, physical examination and anatomic loca-tion are of paramount importance.

Methods: In this pictorial essay we review some of the most frequent benign soft tissue conditions which may be mistaken for malignancy and thus lead to need-less referrals, unnecessary biopsies and great anxi-ety to the patients and their carers. Level of evidence: IV.

KEY WORDS: soft tissue pseudotumours, tumour pitfalls, tumours, MRI, musculoskeletal.

\section{Introduction}

A wide range of tumour-like conditions of the soft tissues may be encountered in clinical practice or when patients undergo radiologic examinations ${ }^{1}$. Although advances in cross sectional imaging (ultrasound, MD$\mathrm{CT}$ and $\mathrm{MRI}$ ) play a pivotal role in the correct evaluation of tumour-like lesions, a systematic approach is needed to achieve a definitive diagnosis or limit the differential diagnosis ${ }^{1-3}$. Clinical history, physical examination and anatomic location are of paramount importance $^{1-3}$. This pictorial essay reviews some of the most frequent benign soft tissue conditions which may be mistaken for malignancy and thus lead to needless referrals, unnecessary biopsies and great anxiety to the patients and their carers. We retrospectively reviewed the imaging examinations on file for all patients who were referred to our institution over a 3-year period (2012-2015) and were diagnosed as having pseudotumours. For classification purposes, benign soft tissue pseudotumours were subdivided into categories (Table 1) as follows: 1. Muscle related; 2. Tendon related; 3. Ligamentaponeurosis related; 4. Synovium related; 5. Dermisepidermis related; 6 . Vascular origin lesions; 7 . Neural related pseudotumours; 8 . Miscellaneous non-tumoral conditions.

\section{Non-tumoral conditions of the muscles that may mimic tumours}

Muscle injuries (acute muscle haematoma, organizing haematoma, myositis ossificans)

Muscle injuries are becoming frequent in every day clinical practice both in the athletic and in non-athletic population ${ }^{4}$. Muscle strains, overuse muscle injuries and contusions may be encountered, and clinical history is usually adequate for the correct diagnosis ${ }^{4}$. Predisposing factors such as coagulation disorders and chronic anticoagulation or antiplatelet therapy can also cause such muscle injuries even without an obvious or high force trauma ${ }^{2-5}$. The most common type of muscle injury is muscle strain, an injury to the musculotendinous junction. Typically, MR imaging shows oedema centered along the musculotendinous junction ${ }^{2-5}$. In more severe muscle strains and contusions, fluid collections, such as haematomas, may develop. In association with grossly interrupted muscle fibers, it may show "masslike" features on MR images in addition to muscle oedema. MR imaging is 
Table I. Soft tissue pseudotumours.

\begin{tabular}{|c|c|}
\hline \multicolumn{2}{|r|}{ SOFT TISSUE PSEUDOTUMOURS } \\
\hline $\begin{array}{l}\text { Nontumoral conditions } \\
\text { of the muscles that may } \\
\text { mimic tumors }\end{array}$ & $\begin{array}{l}\text { 1. Muscle injuries (acute muscle haematoma, organizing haematoma-myositis } \\
\text { 2. Accificans) } \\
\text { 3. Myositis (inflammatory-infectious/muscle abscess) } \\
\text { 4. Muscle herniation }\end{array}$ \\
\hline $\begin{array}{l}\text { Nontumoral conditions } \\
\text { of the tendons that may } \\
\text { mimic tumors }\end{array}$ & $\begin{array}{l}\text { 1. Tendon tears } \\
\text { 2. Avulsion injuries } \\
\text { 3. Tendinopathy } \\
\text { 4. Tenosynovitis } \\
\text { 5. Tendon ganglion cysts }\end{array}$ \\
\hline $\begin{array}{l}\text { Nontumoral conditions } \\
\text { of the ligaments- } \\
\text { aponeurosis that may } \\
\text { mimic tumors }\end{array}$ & $\begin{array}{l}\text { 1. Ligament tears } \\
\text { 2. Ligamentous ganglion cysts } \\
\text { 3. Fibromatosis-Fasciitis }\end{array}$ \\
\hline $\begin{array}{l}\text { Nontumoral conditions } \\
\text { of the synovium that } \\
\text { may mimic tumors }\end{array}$ & $\begin{array}{l}\text { 1. Synovial cysts } \\
\text { 2. Bursae-Bursitis } \\
\text { 3. Synovial "lesions" in inflammatory - deposition diseases } \\
\text { 4. Synovial proliferation disorders }\end{array}$ \\
\hline $\begin{array}{l}\text { Nontumoral conditions } \\
\text { of the dermis-epidermis } \\
\text { that may mimic tumors }\end{array}$ & $\begin{array}{l}\text { 1. Epidermal inclusion cyst } \\
\text { 2. Cellulitis-abscess } \\
\text { 3. Post-traumatic/postsurgical }\end{array}$ \\
\hline $\begin{array}{l}\text { Nontumoral conditions } \\
\text { of vascular origin that } \\
\text { may mimic tumors }\end{array}$ & $\begin{array}{l}\text { 1. Vascular Malformations-Hemangiomas } \\
\text { 2. Aneurysms-Pseudoaneurysms } \\
\text { 3. Varices }\end{array}$ \\
\hline $\begin{array}{l}\text { Nontumoral conditions } \\
\text { of neural origin that may } \\
\text { mimic tumors }\end{array}$ & $\begin{array}{l}\text { 1. Morton's neuroma } \\
\text { 2. Perineural cyst }\end{array}$ \\
\hline $\begin{array}{l}\text { Miscellaneous non- } \\
\text { tumoral conditions }\end{array}$ & $\begin{array}{l}\text { 1. Lymph nodes } \\
\text { 2. Tumoral calcinosis } \\
\text { 3. Foreign body reaction (granuloma/abscess) }\end{array}$ \\
\hline
\end{tabular}

rarely required in the evaluation of acute, simple haematomas, but may be requested in complex cases or in those patients without a clear history of trauma. The MRI appearance depends on the state of the haemoglobin molecule, and whether the haematoma is intra- or extracellular ${ }^{3-5}$. Recognition of areas showing the T1 shortening of methaemoglobin (high signal intensity on T1-weighted MR images) and the T2 shortening of haemosiderin (low signal intensity on T2-weighted MR images), as well as the characteristic signal drop-off or blooming artifact with T2weighted gradient-echo MR sequences, may assist in achieving the correct diagnosis ${ }^{3-5}$. In chronic muscle injuries (weeks to months after the traumatic incident), MR imaging poses difficulties, and differentiation from a soft tissue mass requires evaluation of all physical findings and clinical history details. The methaemoglobin breaks down into haemosiderin and results in decreased signal intensity both on $\mathrm{T} 1$ and T2-weighting. However, the breakdown of blood products is not uniform. Accelerated breakdown is usually noted in the periphery, and reflects a low signal rim whereas, centrally, a more inhomogeneous MR signal intensity is noted. Gradually homogeneity in MR imaging is demonstrated.

Myositis ossificans is a distinct muscle-related entity 


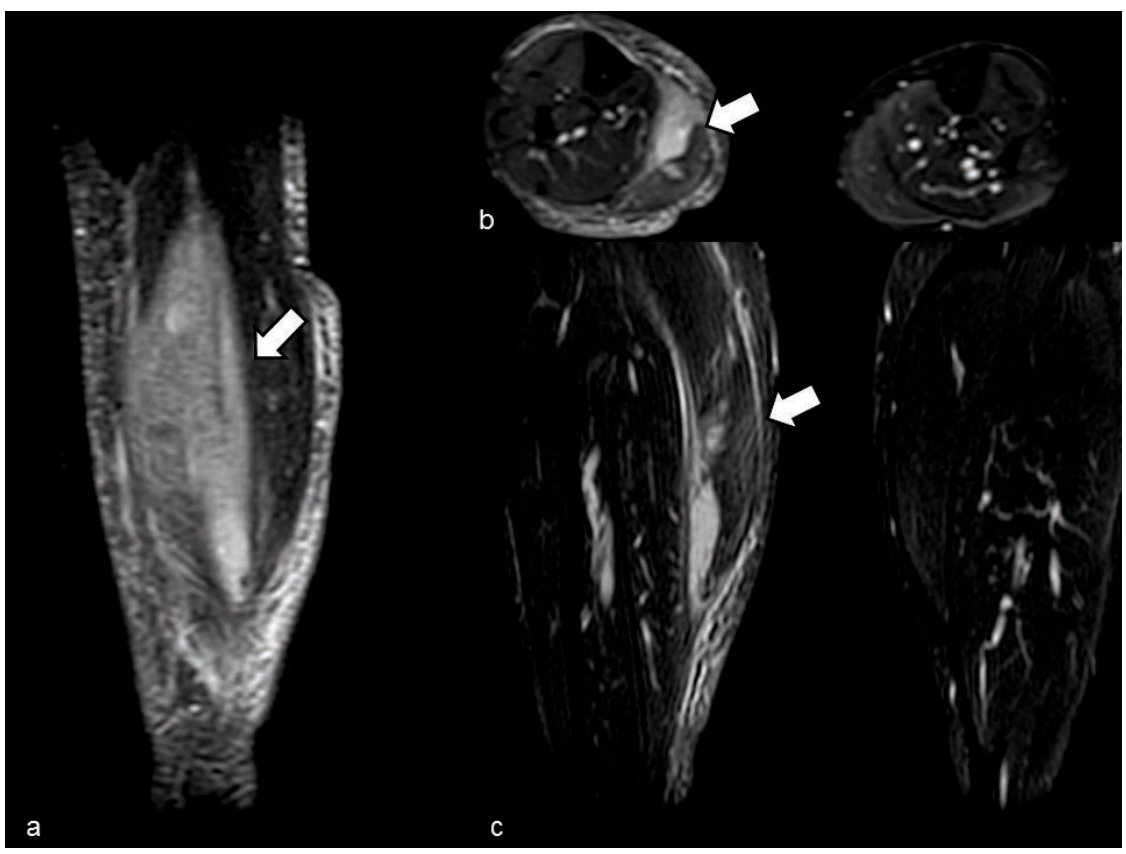

Figure 1 a-c. Acute muscle injury. The patient presented with calf enlargement and pain after a football game. The sagittal a), axial b) and coronal c) STIR MR images demonstrate a typical myofascial injury (arrows) of the gastrocnemious with associated haematoma formation ("tennis leg").

that usually results from trauma, but frequently a straightforward clinical history of trauma is lacking ${ }^{5,6}$. It is characterized by a soft tissue mass that develops characteristic heterotopic peripheral calcification-ossification over a period of 6 to 8 weeks post trauma. $\mathrm{MRI}$ findings are variable, and depend on the chronicity of the lesion. CT scanning is usually the best imaging modality, since it demonstrates the peripheral mineralization at an earlier stage ${ }^{5,6}$. Differentiation from extraosseous, parosteal osteosarcomas and synovial sarcomas is mandatory, and close imaging follow-up is needed. Tumour ossification occurs at the centre of the lesion, and is surrounded by a soft tissue mass, whereas ossification in myositis ossificans first occurs in the peripheral zone (Figs. 1, 2).

\section{Accessory muscles}

Accessory-supernumerary muscles are uncommon anatomic variants that represent supplementary muscles encountered together with the normal musculature $^{7}$. These muscles are usually asymptomatic and are commonly found in the upper and lower extremities. However, in several cases symptoms are caused by mass effect of the supernumerary muscle on adjacent structures such as nerves, vessels, or tendons ${ }^{7}$. In addition, a palpable swelling may necessitate differentiation from a soft tissue tumour. MRI can accurately demonstrate the presence of an accessory muscle and help differentiation from other soft-tissue masses (Fig. 3).

\section{Myositis (inflammatory, infectious-muscle abscess)} Myositis may develop either as a result of inflammation or infection ${ }^{8}$. Autoimmune-induced inflammation, diseases of inherited or acquired metabolic defects, administration or use of certain drugs and toxins, and local or systemic infections may produce muscle related imaging findings and symptoms that may need differentiation from soft tissue masses ${ }^{8,9}$. Currently, $\mathrm{MRI}$ is the imaging modality of choice in the diagnosis of the aforementioned muscular disorders. In inflammatory cases, such as polymyositis and dermatomyositis, the diagnosis is based on a typical clinical history, elevated muscle enzyme titers, and findings on electromyography and physical examination 8-10. MRI shows the extent and intensity of the disease and the distribution of signal changes is usually symmetric but may also be patchy and asymmetric ${ }^{10}$. High signal intensity MR findings are noted in the active phase on STIR and fat-saturated gadolinium-enhanced T1-weighted images; in the chronic phase, fatty atrophy ensues. MRI also shows the best area for muscle biopsy to obtain valuable histological verification $^{8-10}$. Infectious myositis (pyomyositis) is an infection of skeletal muscles that is seen predominantly in immunocompromised patients ${ }^{9}, 10$. It may also be encountered in immunocompetent patients, but in such cases it results either secondary to hematogenous spread or from direct spread after skin laceration (either post-traumatic or iatrogenous) ${ }^{9}, 10$. Staphylococcus aureus is the most common pathogenic cause ${ }^{9,10}$. On MRI, hyperintense T2-weighted focal lesions with massive perilesional oedema that may progress to abscess formation are noted. Gadolinium administration is required for the assessment of the infectious process mentioned above. Clinical history, physical examination and correlation of laboratory results with MRI is necessary in reaching the correct diagnosis, since soft tissue masses with necrosis or central liquefaction may have the same MR imaging findings with muscle abscesses (Figs. 4-6). 


\section{E. Perdikakis et al.}
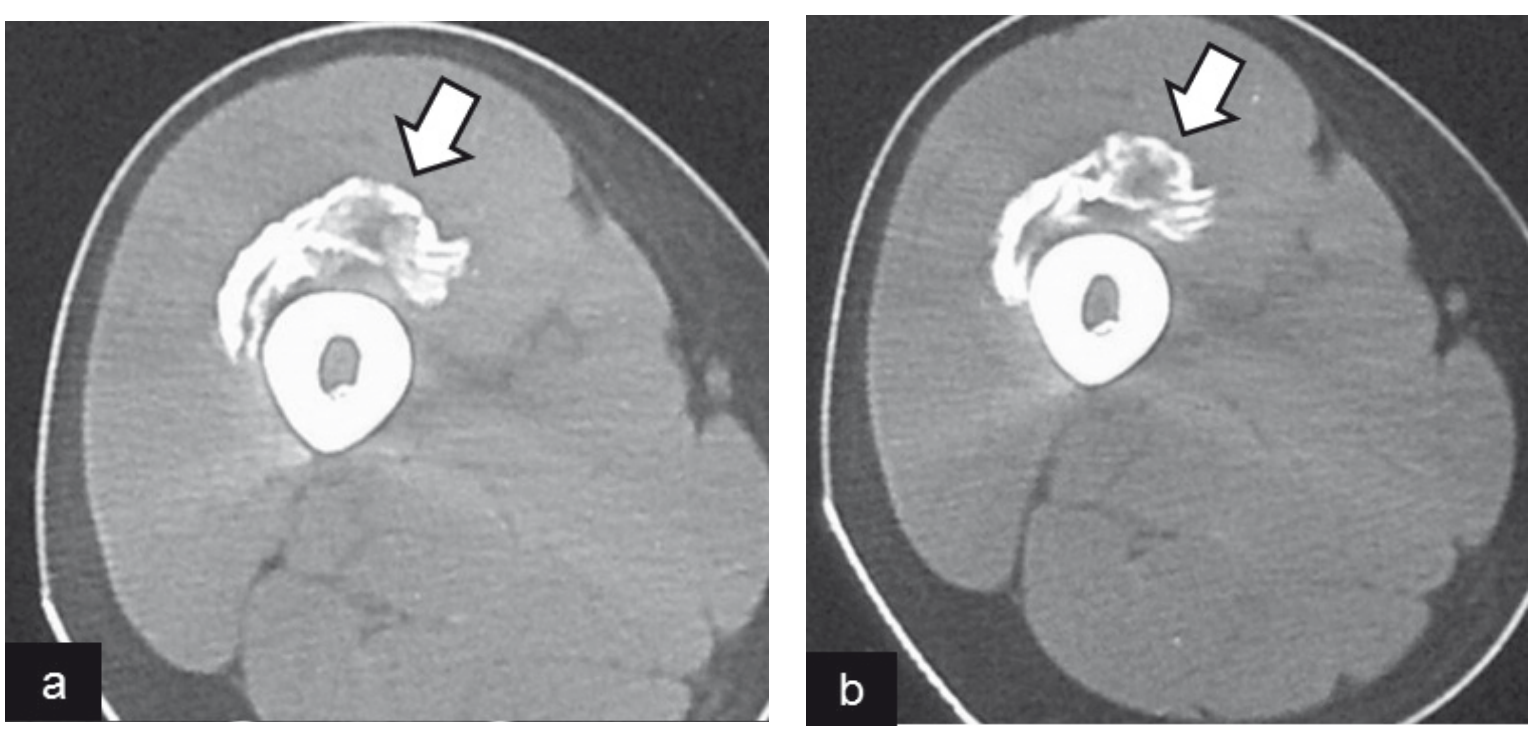

Figure $2 \mathrm{a}$, b. Chronic muscle injury-myositis ossificans. The patient was referred for soft tissue calcification in the anterior compartment of the leg. The axial MDCT images $(a, b)$ demonstrate ossification in the anterior femoral compartment (arrows). Clinical history revealed muscle injury 4 years ago.

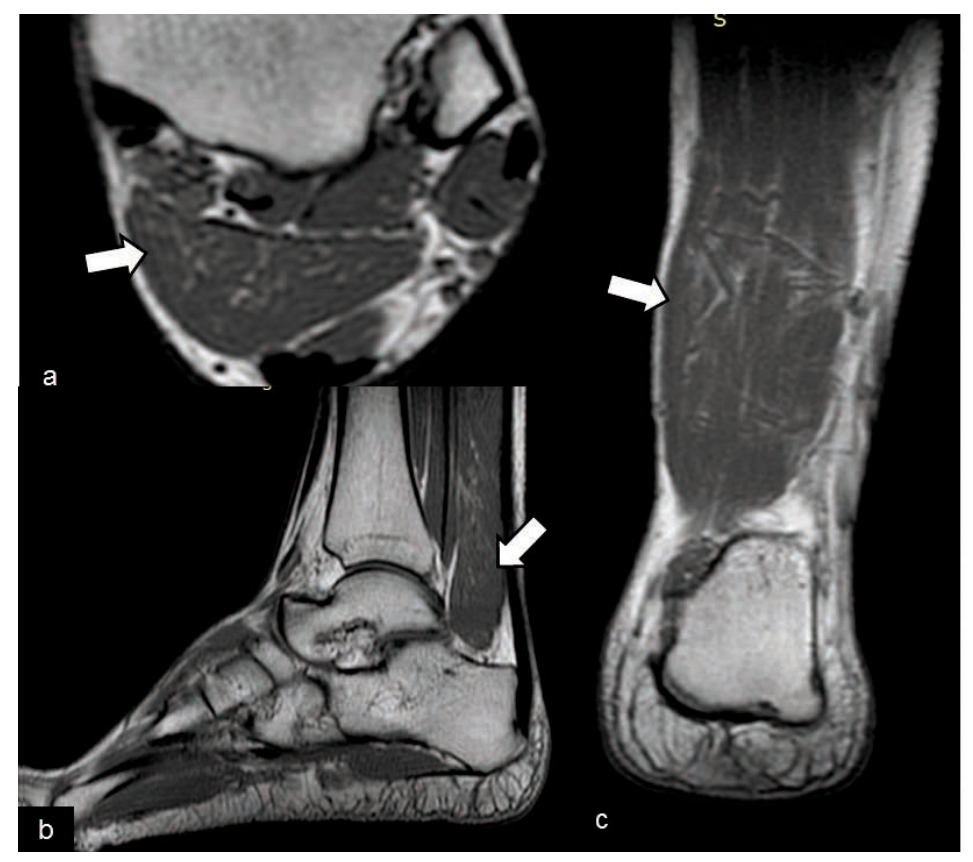

Figure 3 a-c. Accessory soleus muscle. The patient was referred for a "palpable mass" in the lower leg. The axial a), sagittal b) and coronal c) T1-weighted MR images demonstrate an anatomical variation with the presence of an accessory soleus muscle, in accordance with the palpable finding (arrows).

\section{Muscle herniation}

Muscle hernias are the result of myofascial defects that are commonly posttraumatic, but they can also be congenital ${ }^{11,12}$. They are most frequently found in the lower extremities, and represent a focal fascia defect with protrusion of normal muscle fibers through this defect ${ }^{11-}$

13. Muscle hernias are classically asymptomatic, but sometimes cause pain or cramping sensations with muscle activity. They may also present as a "palpable mass", and the patient is subsequently referred for imaging evaluation. MRI may be prescribed in such cases, but shows normal muscle findings and adds little to the final diagnosis. Musculoskeletal ultrasound is the modality of choice in the evaluation of suspected muscle hernia, since it allows dynamic evaluation of the mass and requested active contraction of the involved muscle during real time sonography reveals or accentuates the lesion², 12 (Fig. 7). 


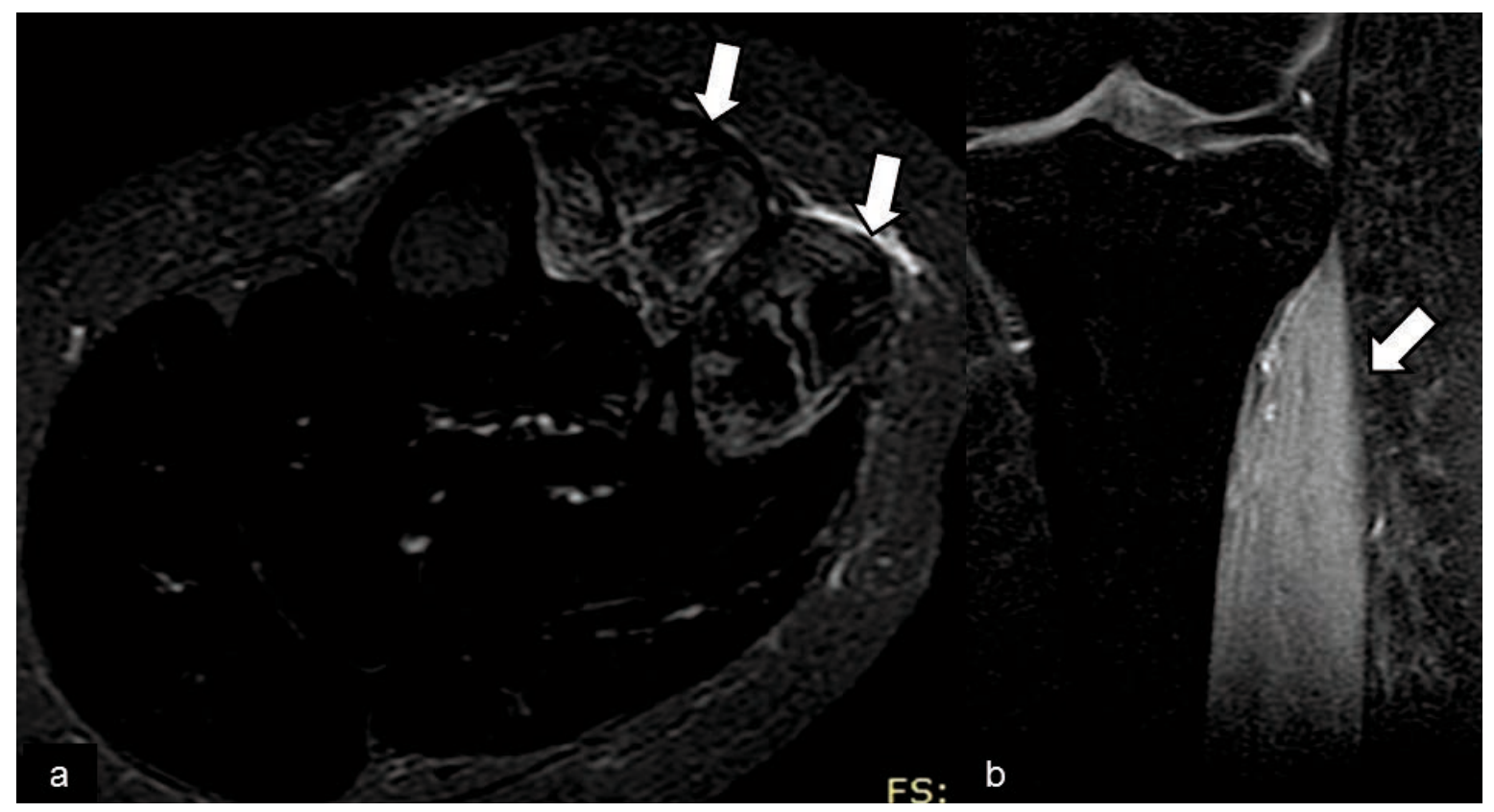

Figure 4 a, b. Denervosing myositis. The axial (a) STIR and the coronal (b) contrast enhanced fat saturated T1-weighted MR images show muscle edema in the anterior compartment of the lower leg in a patient with nerve palsy of the common peroneal nerve.

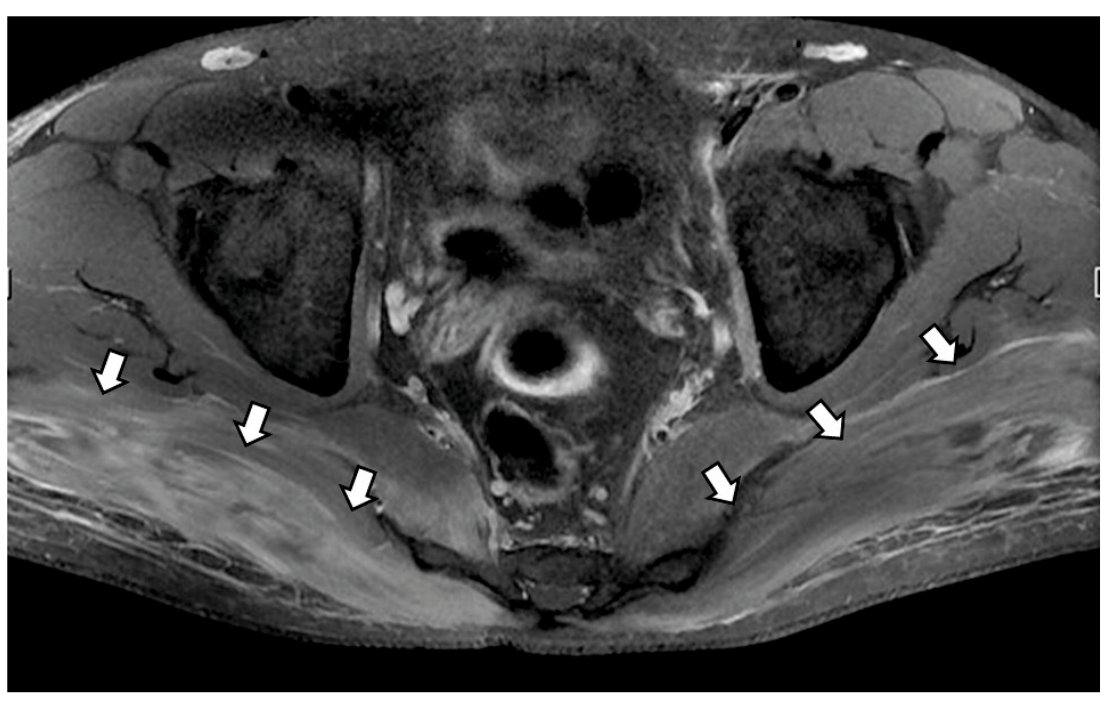

Figure 5. Inflammatory myosistis. The axial PD-weighted fat saturated MR image shows bilateral muscle oedema in the gluteus maximus in a patient with dermatomyositis.

\section{Non-tumoral conditions of the tendons that may mimic tumours}

Tendon tears

Tendon tears usually occur after an eccentric muscle contraction $11,12,14,15$. Spontaneous rupture has also been described in patients with underlying predisposing metabolic disorders such as chronic renal failure, hyperparathyroidism, diabetes, gout and systemic lupus erythematosus ${ }^{11}, 12,14,15$. The rupture typically occurs near the musculotendinous junction, and MRI can help in identifying and categorizing it as partial or complete tear ${ }^{16}$, thus influencing the prognosis, because a delay in surgical reconstruction is believed to adversely affect outcome ${ }^{11,12,14,15}$. Furthermore, in neglected cases or when clinical history is not clear, tendon tears may be mistaken clinically as soft tissue masses, and MRI nicely depicts the tendon tear, reassuring the patient and the referring physician (Fig. 8).

\section{Avulsion injuries}

Avulsion injuries usually affect young adolescents involved in sport activities $4-6,11,12,14,15,17$. Acute or chronic avulsion injuries of the immature skeleton lead 


\section{E. Perdikakis et al.}

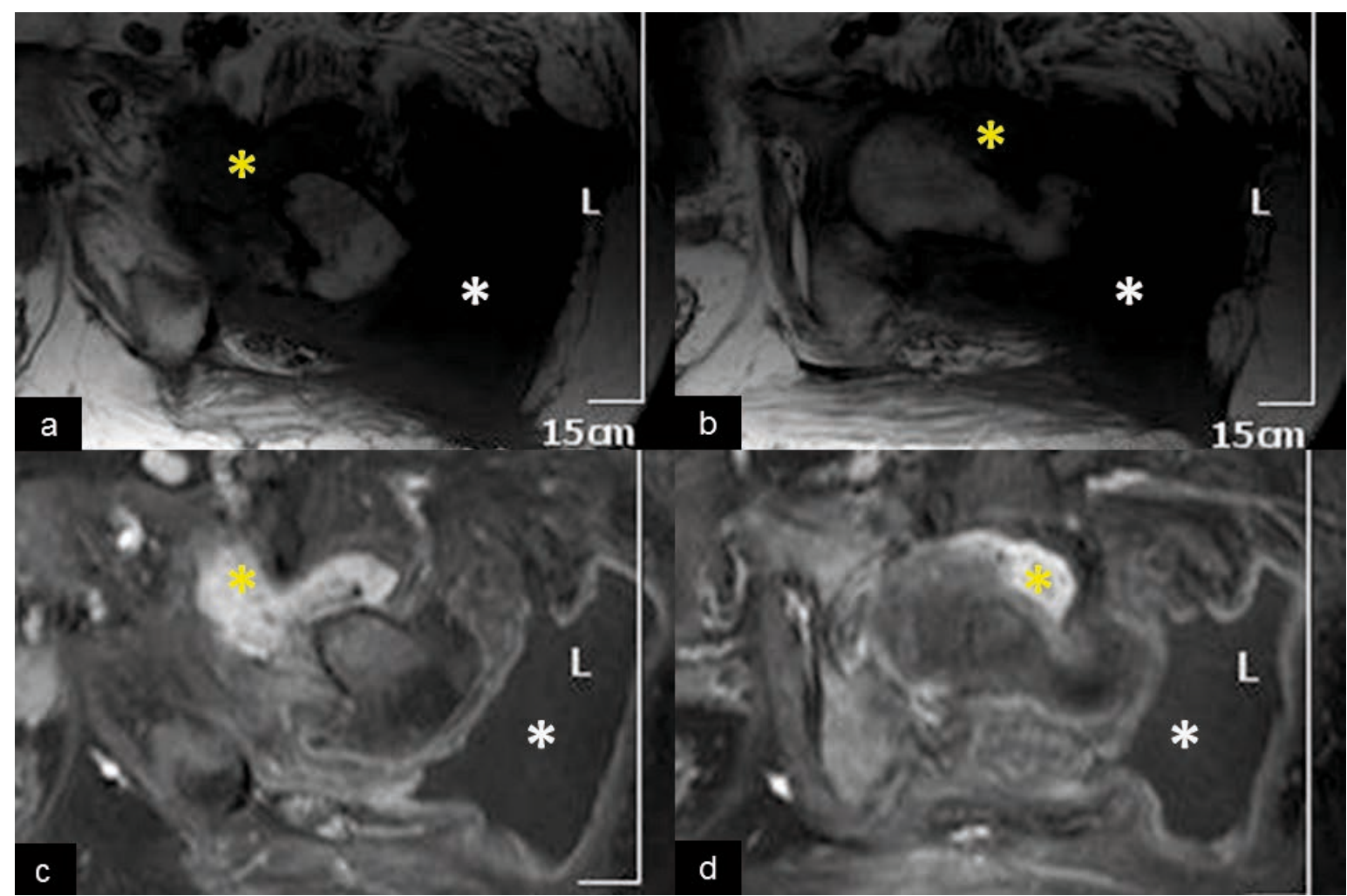

Figure 6 a-d. Infectious myositis-abscess. The axial (a, b) T1-weighted and the axial (c, d) fat saturated contrast enhanced T1-weighted MR images show the presence of muscle abscess (asterisks) in an immunocompromised patient. CT aspiration and culture verified Staphylococcus Aureus as the underlying pathogen [please note associated septic arthritis (yellow asterisks) in the images].

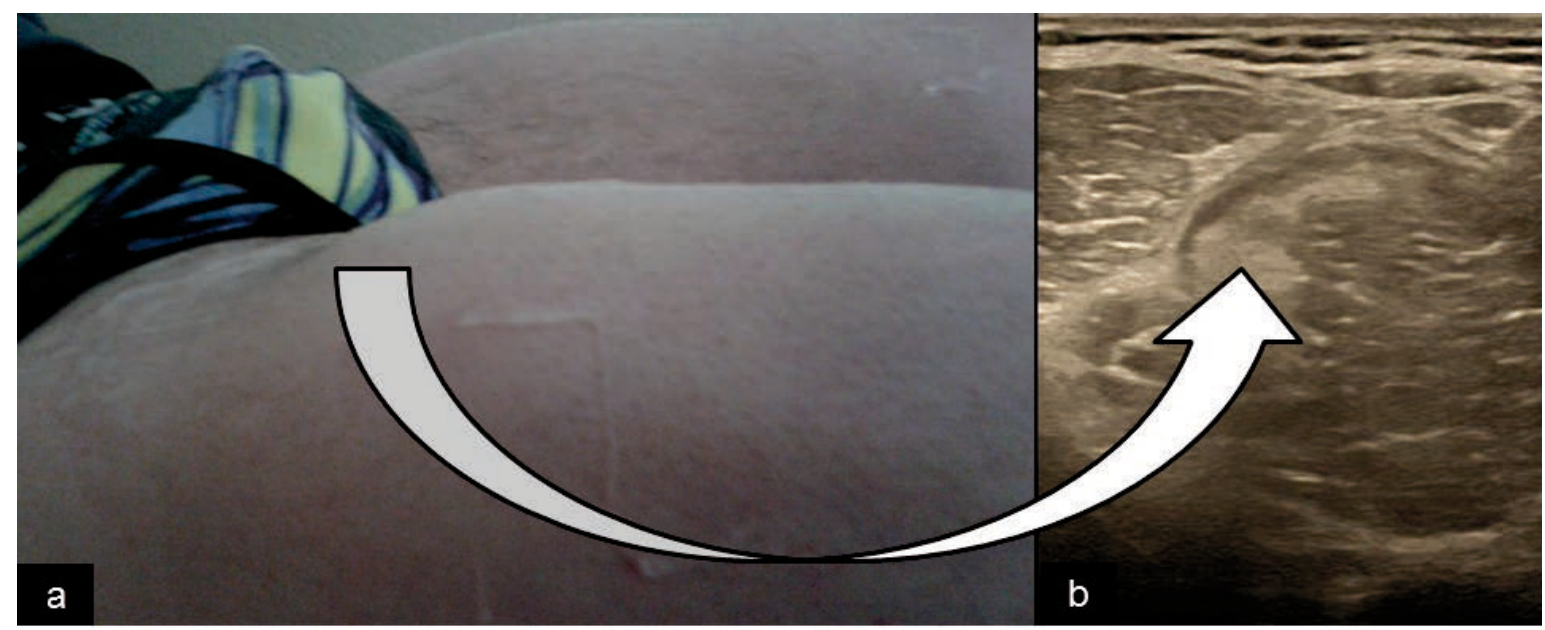

Figure 7 a, b. Muscle herniation. The patient was referred for MRI with the suspicion of a "thigh mass". The photograph of the patient's thigh during muscle contraction (a) and the associated US image (b) demonstrated muscle herniation (curved arrow) through an intermuscular fascial defect.

to bone overgrowth, bone fragmentation at the site of insertion of the tendon, and associated tendinopathy and peritendinitis, which can be painful, and mistaken as soft or bone related tumour $4-6,11,12,14,15,17$. They are most commonly encountered in the pelvis and the lower extremities and their MR appearance depends on the chronicity of the injury. Plain radiographs and CT imaging may demonstrate the avulsed bony fragment in the acute phase, and help narrowing the differential diagnosis in the subacute-chronic phase, when MR imag- 


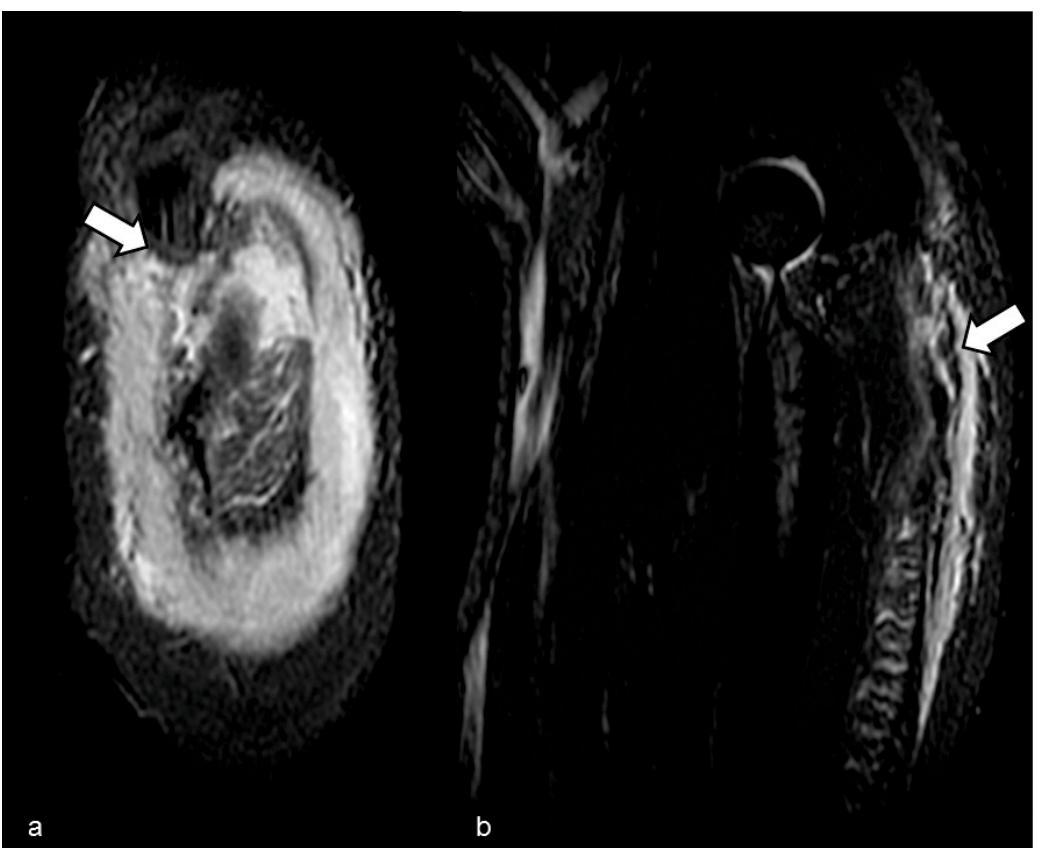

Figure 8 a, b. Tendon tear. The patient was a heavy weight lifting athlete that presented with a palpable "mass" posterior to the elbow joint. The coronal (a) and the sagittal (b) STIR MR images showed the torn and retracted triceps tendon (arrows).

ing findings resemble more aggressive lesions such as neoplasms and infection. Knowledge of the normal anatomy and clinical history will assist the radiologist in making the accurate diagnosis obviating thus the need for biopsy (Fig. 9).

\section{Tendinopathy}

Tendinopathy is common especially in young active patients involved in sports ${ }^{11}, 12,14,15$. Tendon thickening, peritendinous oedema and pain may be mistaken as a soft tissue or tendon related tumour. Acute tendinopa-

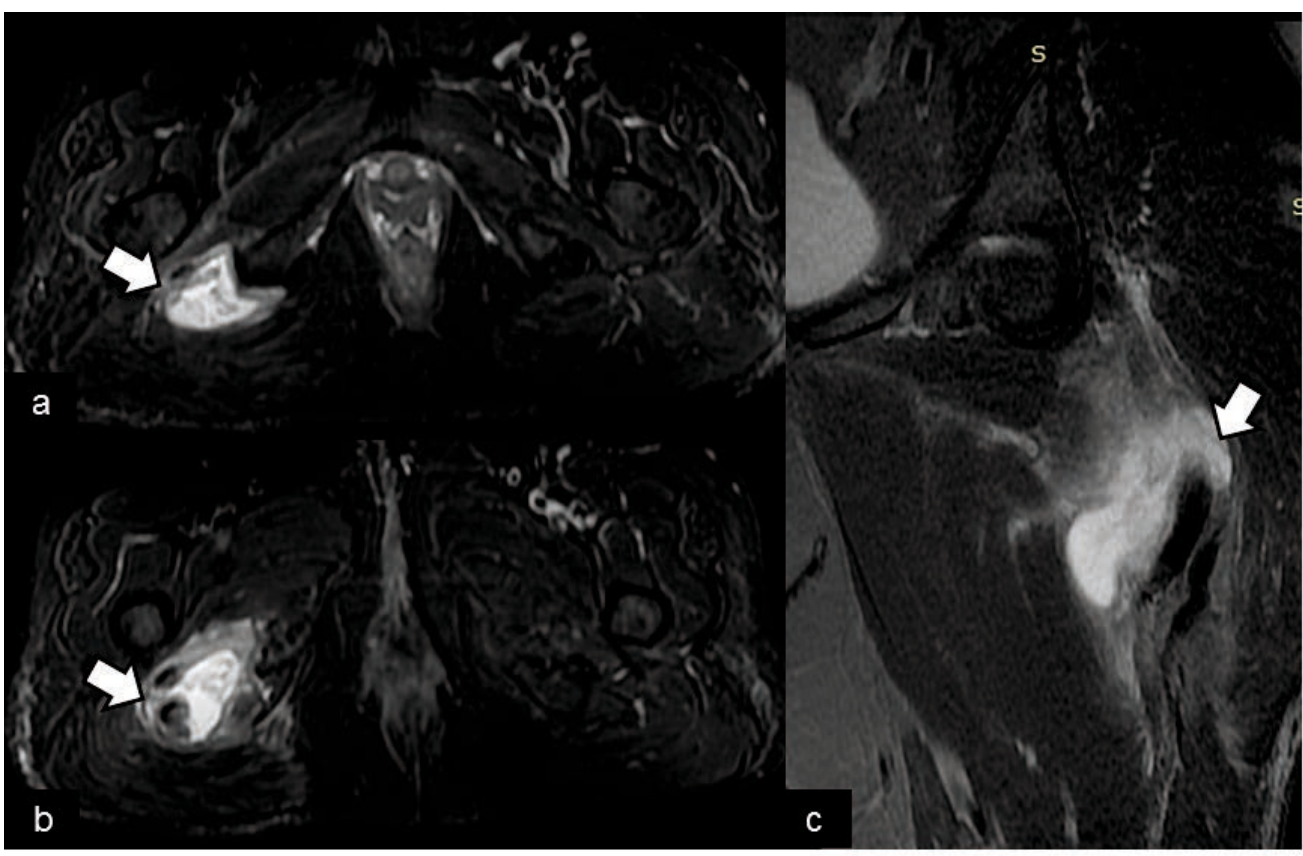

Figure 9 a-c. Avulsion tendon tear. The patient presented with palpable "mass" and ecchymosis-skin discoloration in the thigh area. The transverse $(a, b)$ STIR and the sagittal (c) PD-weighted fat saturated MR images showed hamstrings avulsion injury (arrows). 


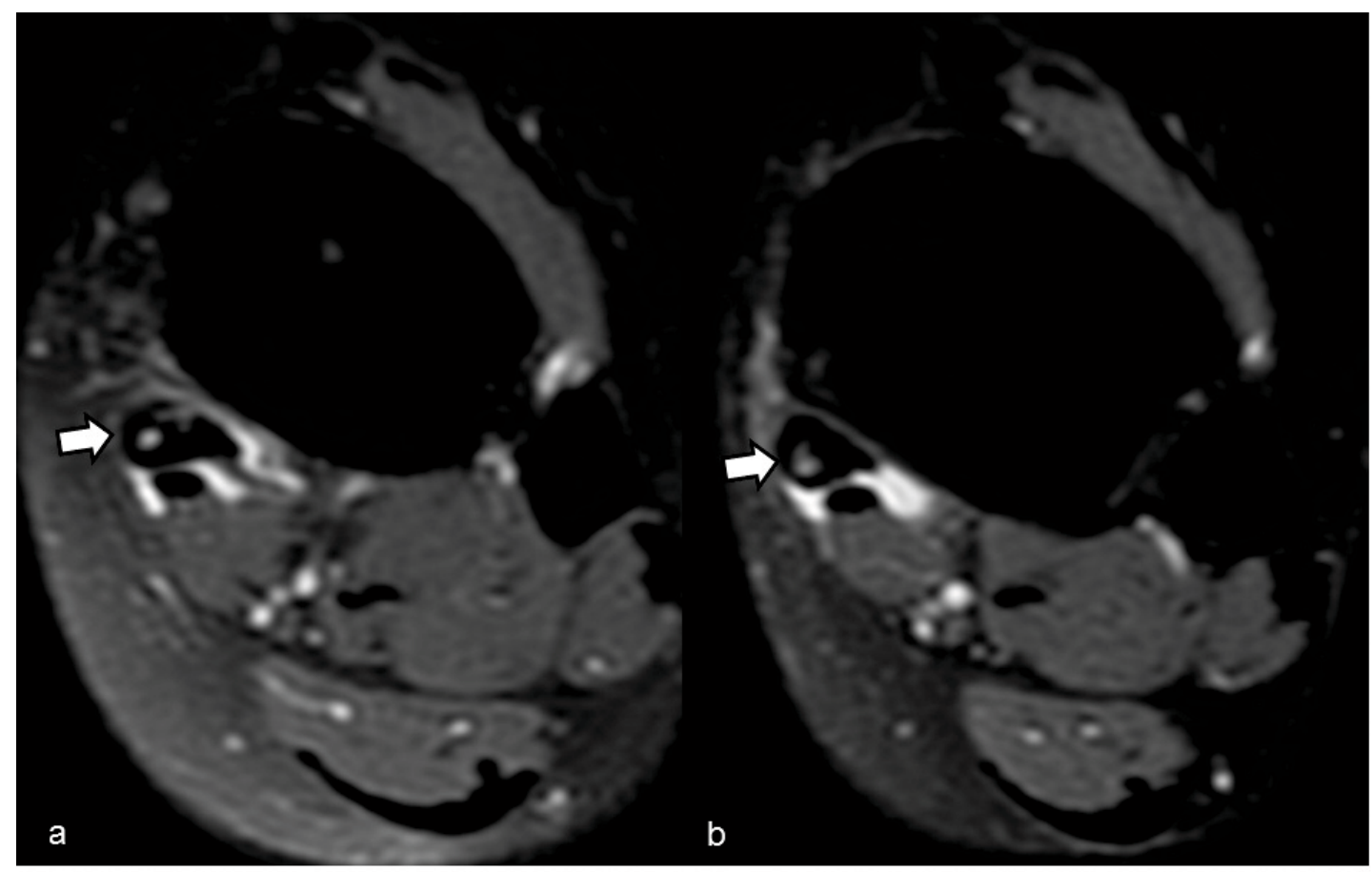

Figure 10 a, b. Tendinopathy-Tenosynovitis. The axial (a, b) PD-weighted fat saturated MR images demonstrated posterior tibialis tendinopathy (arrows) with intrasubstance split tear and associated tenosynovitis. The patient was a professional dancer that presented with a "tender mass" in the ankle area.

thy is the result of repetitive microtrauma, and is characterized by inflammatory changes ${ }^{11}, 12,14,15$. On the other hand, mucoid degeneration with poor healing response and without an associated frank inflammatory process is evident in chronic forms ${ }^{11}, 12,14,15$. MRI features include thickening of the tendon and signal alterations both on T1-weighted and T2-weighted sequences in the acute-subacute phase ${ }^{18}$. In chronic-neglected cases, the entire tendon may be involved, and may be mistaken clinically as a palpable mass. However, MRI demonstrates characteristically a fusiform thickening of the tendon with altered signal intensity in both T1-weighted and T2-weighted sequences ${ }^{19}$ (Fig. 10).

\section{Tenosynovitis}

$\mathrm{MRI}$ is considered the most sensitive imaging modality for early detection of tenosynovitis ${ }^{20,21}$. Nevertheless, the MR imaging findings in tenosynovitis are nonspecific, and synovial fluid aspiration or synovial membrane biopsy is mandatory for definitive diagnosis 20,21 . MR imaging typically demonstrates tendon thickening along with enhancing synovium. The inflammatory signal changes in the tendon sheath are usually correlated with oedema in the surrounding soft tissues. Thus, differentiation from soft tissue masses is often required together with demonstration of the extent of the disease. T1-weighted post-gadolinium injection sequences are particularly useful to differentiate the thick tenosynovium from the surrounding structures and assists in the correct diagnosis. In cases of infectious tenosynovitis, $\mathrm{MRI}$ can also depict the spread of infection from the tendon compartments to the adjacent soft tissues, bone or joint, a finding that influences therapeutic management and subsequent surgical approach (Fig. 10).

\section{Tendon ganglion cysts}

Tendon ganglion cysts are defined as benign cystic lesions that usually arise from the tendon sheath, are surrounded by dense connective tissue, and are filled with a gelatinous fluid rich in hyaluronic acid and other mucopolysaccharides ${ }^{22,23}$. At MRI, the lesion may be rarely interspersed within the tendon fibers, but usually occurs along the tendon sheath (tendon sheath ganglion cysts), and thus the MR imaging appearance is fairly typical 22,23 . On T2-weighted MR images, ganglia appear with high signal intensity, whereas, on T1weighted MR images, the signal intensity of ganglia depends on their protein content. Associated bony erosion and pericystic oedema have been reported. In such instances, differentiation from more aggressive soft tissue 'masses" may be required ${ }^{22,} 23$ (Fig. 11).

\section{Non-tumoral conditions of the ligaments-aponeu- rosis that may mimic tumours}

\section{Ligament tears}

MRI can provide valuable information for diagnosis and evaluation of ligamentous tears ${ }^{24}$. In general, normal ligaments demonstrate low signal intensity on MR sequences, whereas disruption manifests as altered signal intensity and loss of typical ligamentous anatomy ${ }^{24}$. Familiarity with the fine anatomy of the ligament is cru- 


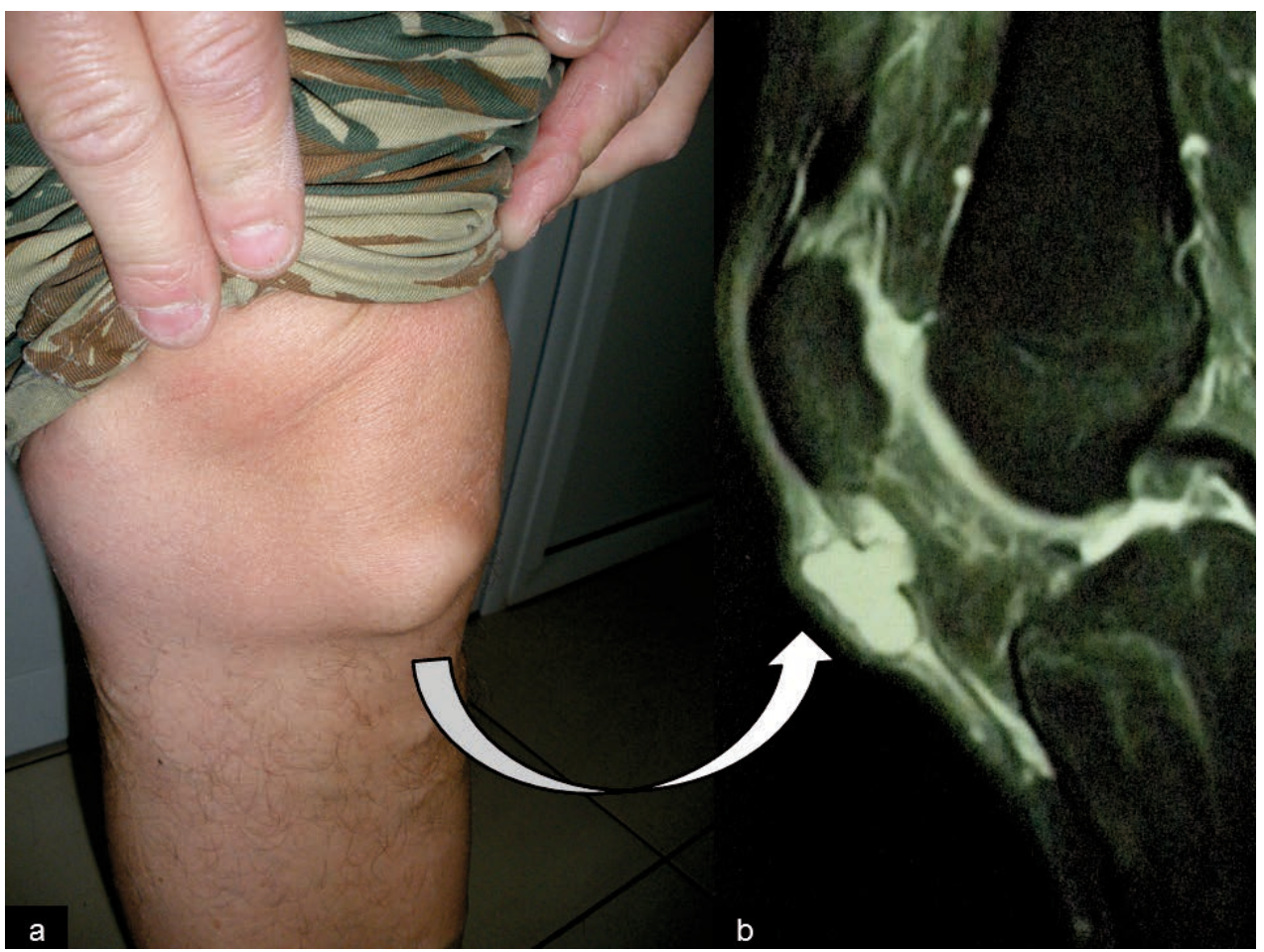

Figure $11 \mathrm{a}$, b. Tendinopathy-ganglion cyst. The patient presented with a "hard-immobile mass" (a) bellow the inferior pole of the patella. The sagittal (b) PD-weighted fat saturated MR image showed chronic patellar tendinopathy with partial tear and an associated multilocular peritendinous ganglion cyst (curved arrow) that corresponded to the palpable clinical finding.

cial for identifying partial or complete tear. In addition, an optimal MR imaging technique should include proper extremity positioning, dedicated surface coils, and specific MR protocols for identification of the suspected tear, especially in stabilizing ligamentous elements of small joints 24,25 . Associated soft tissue oedema and altered anatomy may simulate a more aggressive procedure, and thus MR imaging is a powerful method for evaluating acute and chronic ligament tears (Fig. 12).

\section{Ligamentous ganglion cysts}

As with tendon ganglion cysts, they are cystic lesions, and typically arise from chronic traumatic injury of the ligament ${ }^{22-25}$. Part of the lesion may be interspersed within the ligament fibers, or lying entirely adjacent to the ligament, or it may extend occasionally in the surrounding soft tissues. An unilocular or multilocular appearance has been described, and MRI is the modality of choice for correct identification, especially in lesions located in the deep soft tissues $22-25$ (Fig. 13).

\section{Fibromatosis-Fasciitis}

Ligamentous aponeuroses may undergo a post-traumatic proliferative process with the most common location in the plantar aponeurosis ${ }^{1-3}, 26$. Plantar fasciitisplantar fibromatosis occur in the proximal insertional site and in the central portion of the medial plantar aponeurosis of the foot and represent one of the most common causes of heel pain. It has been related to other forms of superficial fibromatoses (e.g.,
Dupuytren's contracture, Peyronie's disease), and may coexist with these fibromatoses in the same patient. Bilateral lesions are also common 1-3, 26. At MR imaging, fasciitis-fibromatosis is depicted as a nodular lesion located in the involved aponeurosis with decreased signal intensity on both T1-weighted and T2-weighted images. Proximal lesions at the aponeuroseal insertion are associated with bony alterations (i.e. spurs) or subcutaneous oedema (Figs. 14, 15).

\section{Non-tumoral conditions of the synovium that may mimic tumours}

\section{Synovial cysts}

Synovial cysts are defined as juxta-articular cystic fluid collections that are lined by synovial cells. This synovial lining is the characteristic histological feature that distinguishes them from other juxta-articular cyst-like fluid collections $^{22,23}$. In terms of pathophysiology, a synovial cyst represents a focal extension-herniation of joint fluid that may extend in any direction, and may communicate with the joint ${ }^{22,} 23$. They are usually incidental findings on MR examinations, but, regarding their aetiology, they have been associated with other underlying joint disorders such as osteoarthritis, trauma and rheumatoid disorders. Even though they are usually asymptomatic, they can manifest with pain and swelling, especially if they compress adjacent anatomic structures. They may have a unilocular or multilocular MR appearance, with signal intensity similar to joint flu- 


\section{E. Perdikakis et al.}

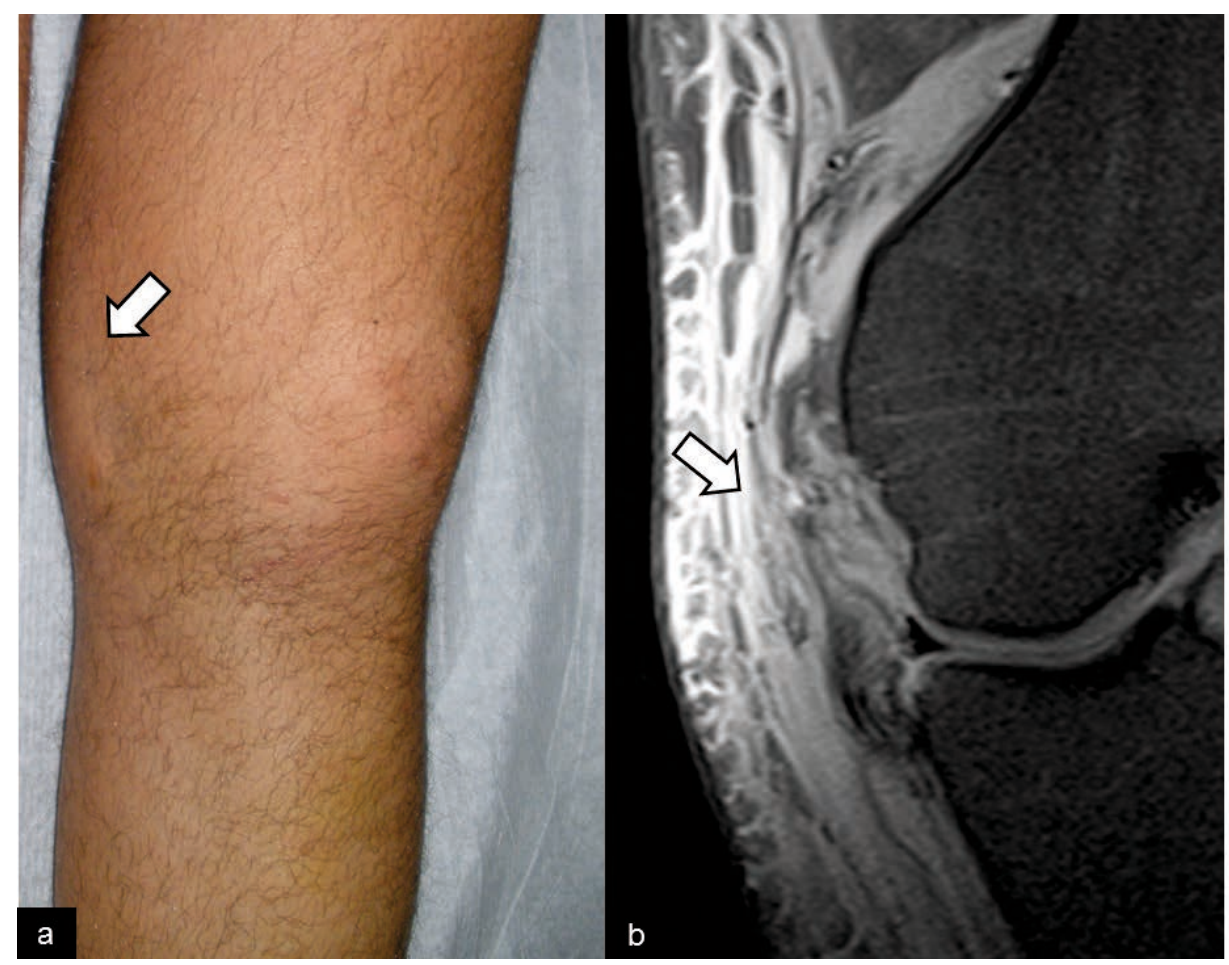

Figure $12 \mathrm{a}$, b. Ligament tear. The patient presented with knee enlargement (arrow in a) and pain after a twisting accident in sports. The coronal (b) PD-weighted fat saturated MR image showed complete disruption of the MCL (arrow in b).

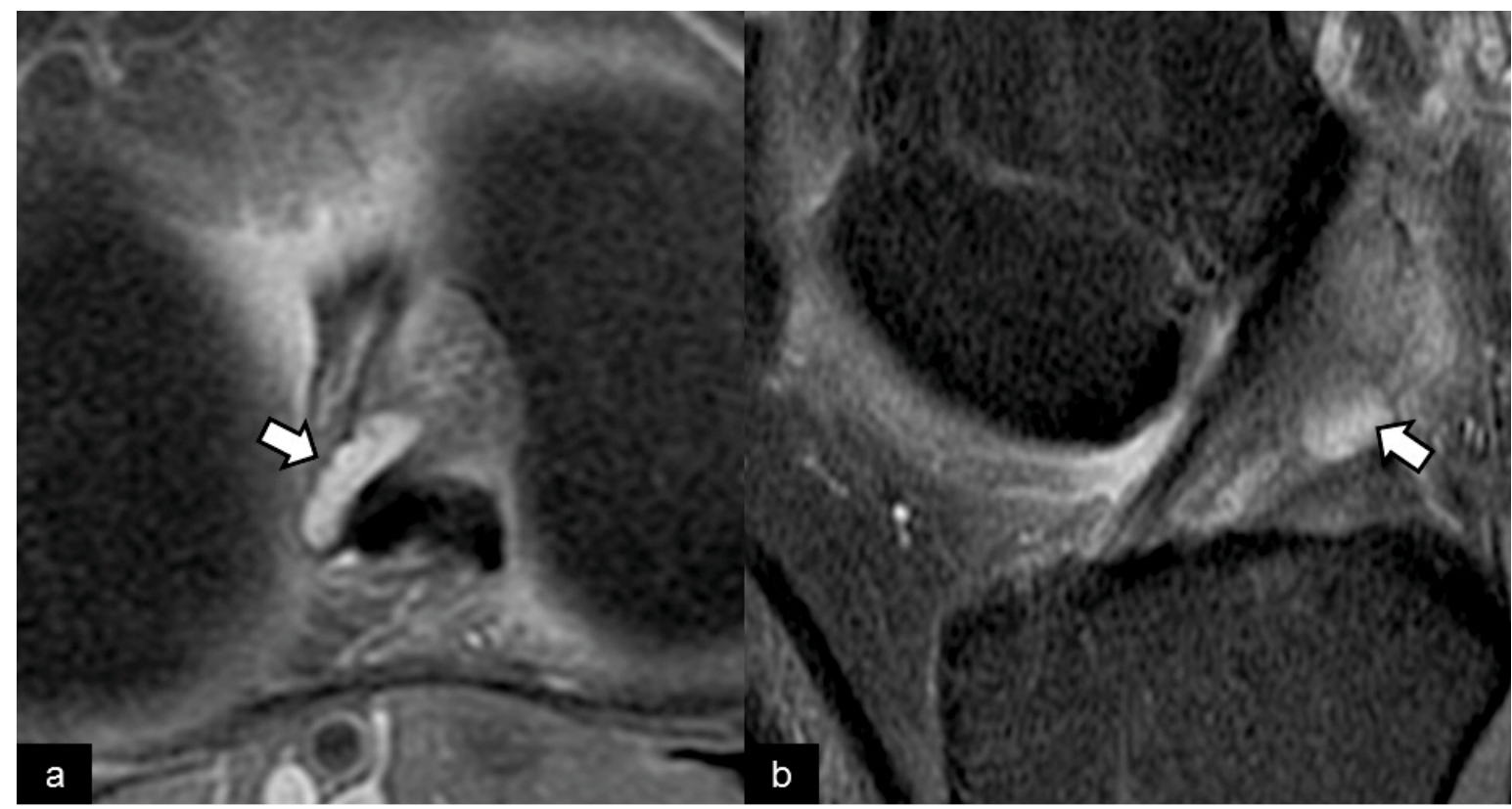

Figure 13 a, b. Ligamentous ganglion cyst. The axial (a) and the sagittal (b) PD-weighted fat saturated MR images demonstrate an ACL ganglion cyst (arrows).

id 22, 23. However, in complicated cases (i.e. when infected or manifest intracystic haemorrhage), they may resemble a complex soft tissue mass, and differential diagnosis from other cyst-like lesions is required with a dedicated contrast-enhanced MRI examination protocol (Fig. 16). 


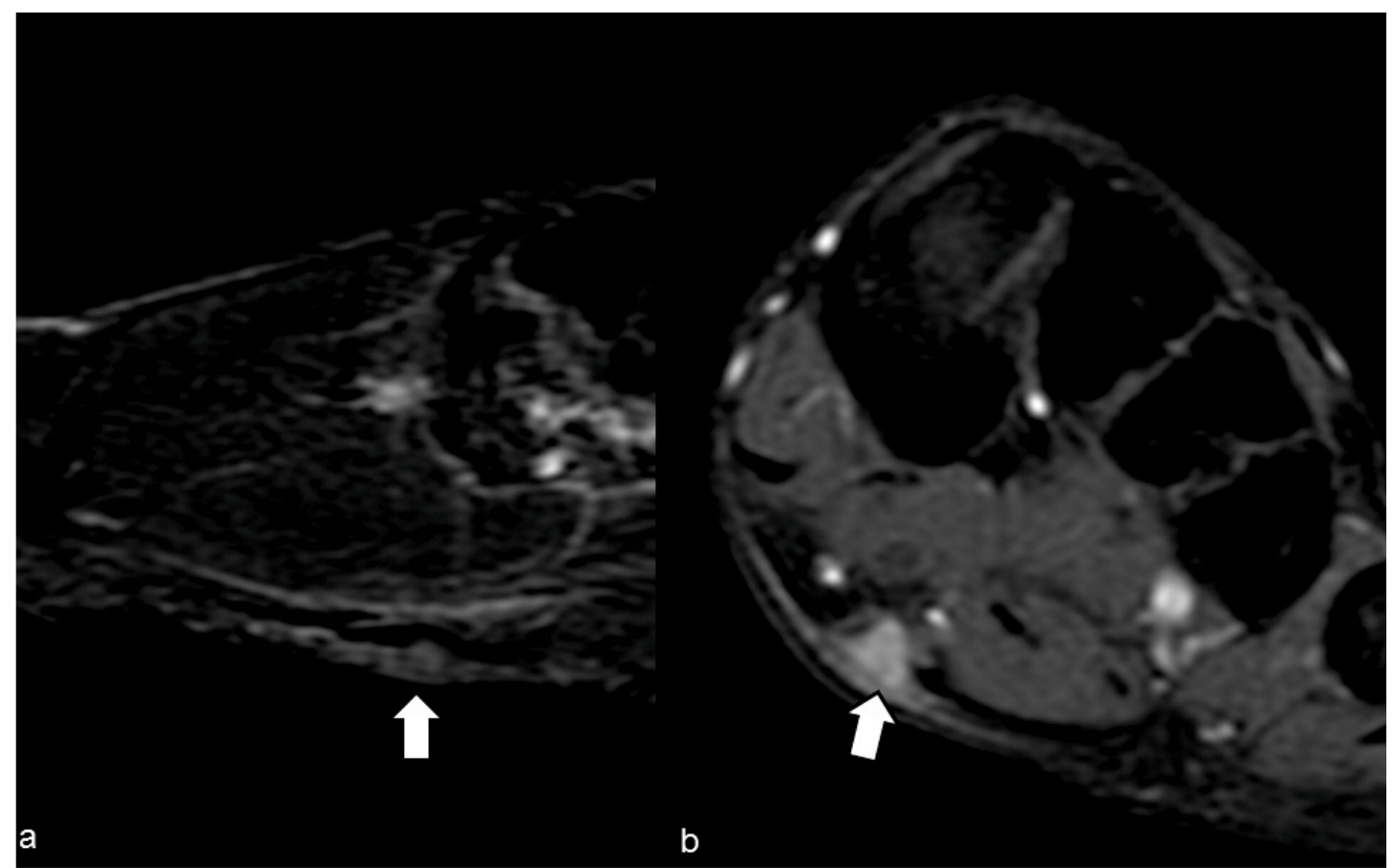

Figure 14 a, b. Plantar fibromatosis. The sagittal (a) STIR and the axial (b) contrast enhanced fat saturated T1-weighted MR images demonstrate fibromatosis (arrows) of the plantar aponeurosis.

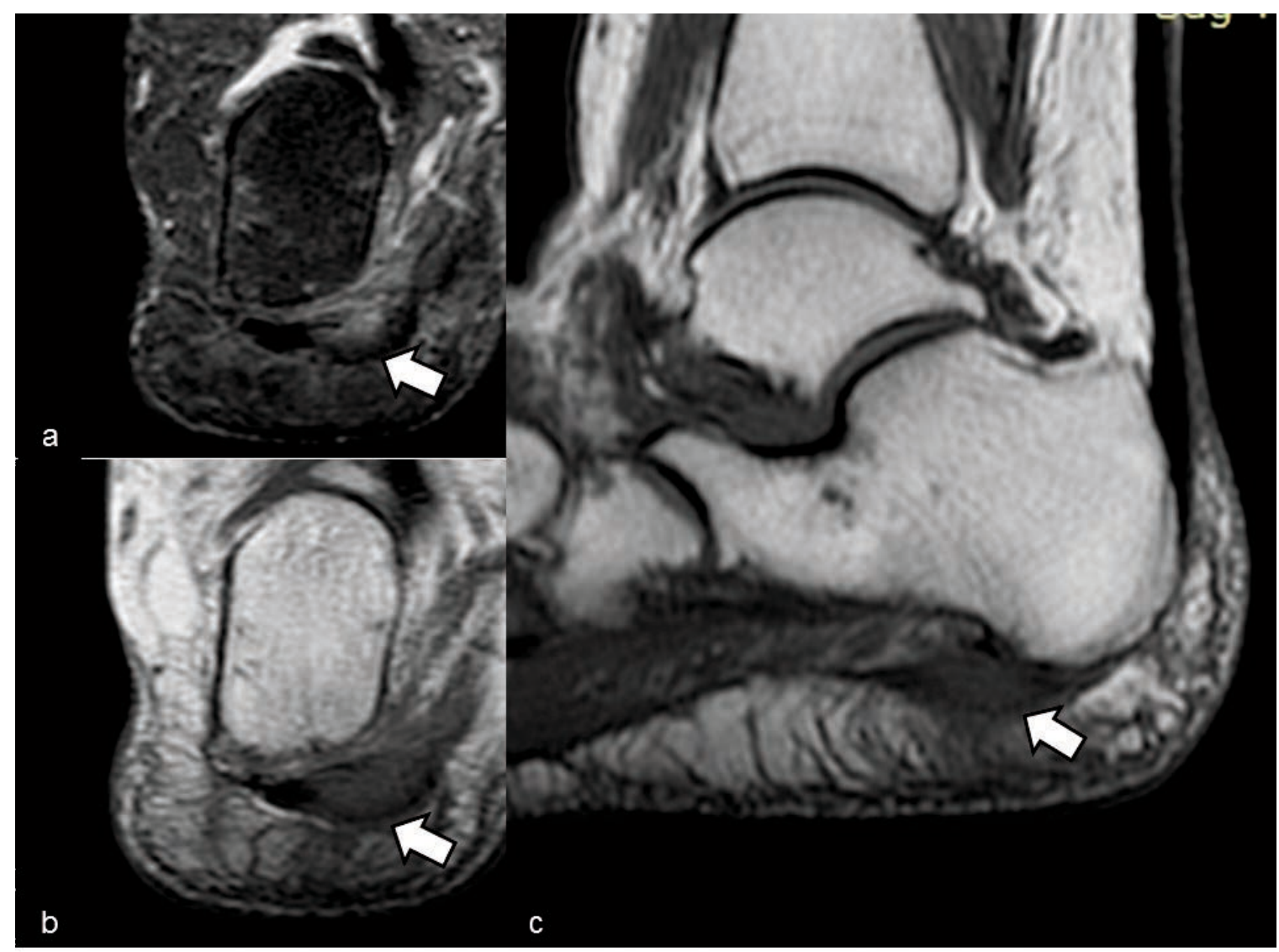

Figure 15 a-c. Plantar fasciitis. The coronal (a) STIR, the coronal (b) T1-weighted and the sagittal (c) T1-weighted MR images demonstrate focal thickening and inflammation at the calcaneal insertion (arrows) of the medial plantar aponeurosis. 


\section{E. Perdikakis et al.}
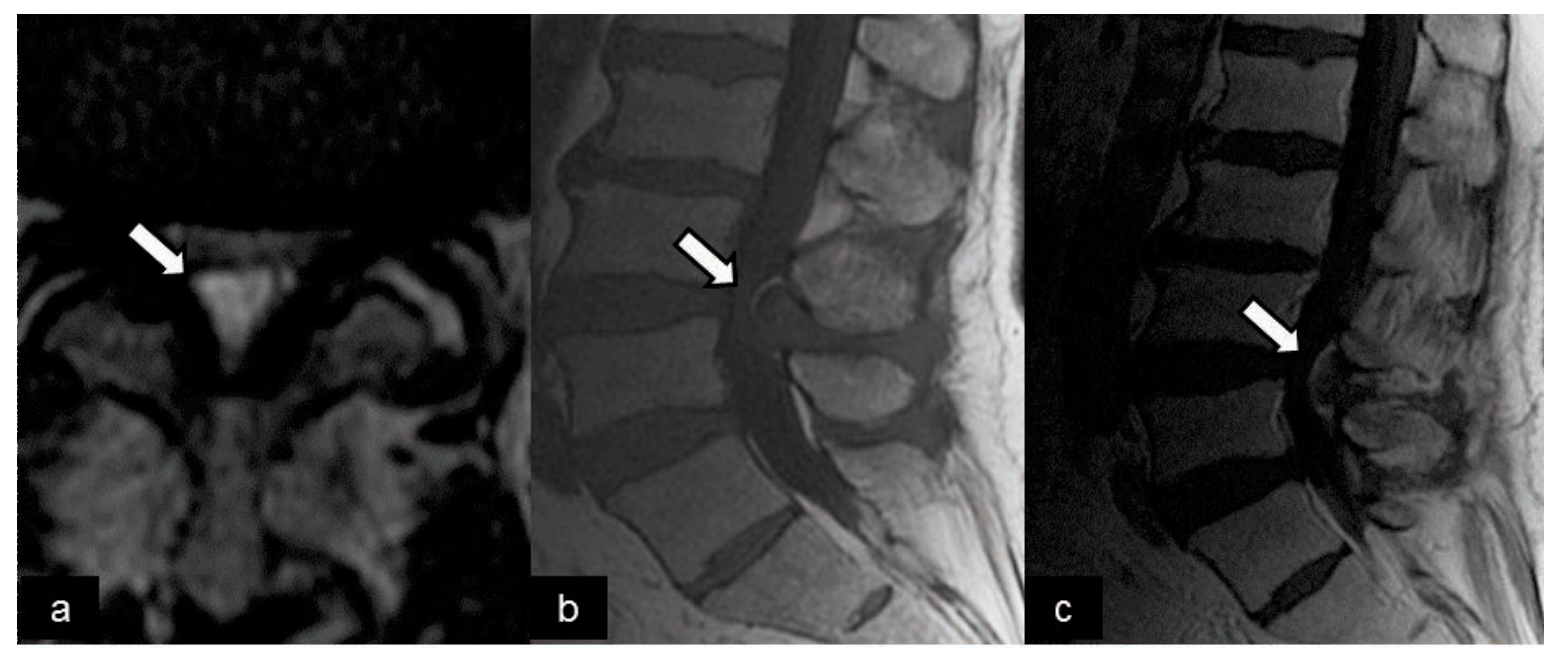

Figure 16 a-c. Synovial cyst. The axial (a) T2-weighted, the sagittal (b) T1-weighted and the sagittal (c) contrast enhanced T1-weighted MR images show a midline synovial cyst (arrows) in a patient with degenerative changes of the posterior spinal elements (Baastrup's disease).

\section{Bursae-Bursitis}

Bursae are normal synovium-lined structures encountered around the joints. Their function is to reduce the friction between adjacent moving structures, such as tendons, ligaments and bony surfaces 22,23 . They are usually collapsed or may often contain a small amount of synovial fluid. Typically, they are not visible on MRI examinations, unless they become inflamed ${ }^{22,} 23$. In such instances, differentiation from soft tissue masses may be necessary (Fig. 17).

Synovial lesions in inflammatory-deposition diseases Inflammatory arthropathies may result in non-tumoral soft-tissue abnormalities in and around the joints as well as subarticular marrow abnormalities that may be mistaken as true masses ${ }^{27}$. Various rheumatic arthropathies (i.e. rheumatoid arthritis) may produce MR imaging findings suggestive of soft tumour in intraarticular and juxta-articular locations, mainly due to synovitis and loose bodies ${ }^{27}$. Calcium deposition disorders (hydroxyapatite, gout and calcium pyrophosphate dehydrate crystal deposition) may also produce MR images of pseudotumours. Haemophilic arthropathy and metabolic disorders such as amyloid deposition arthropathy and primary or secondary hyperparathyroidism may also give the impression of pseudotumours at MRI. Re-

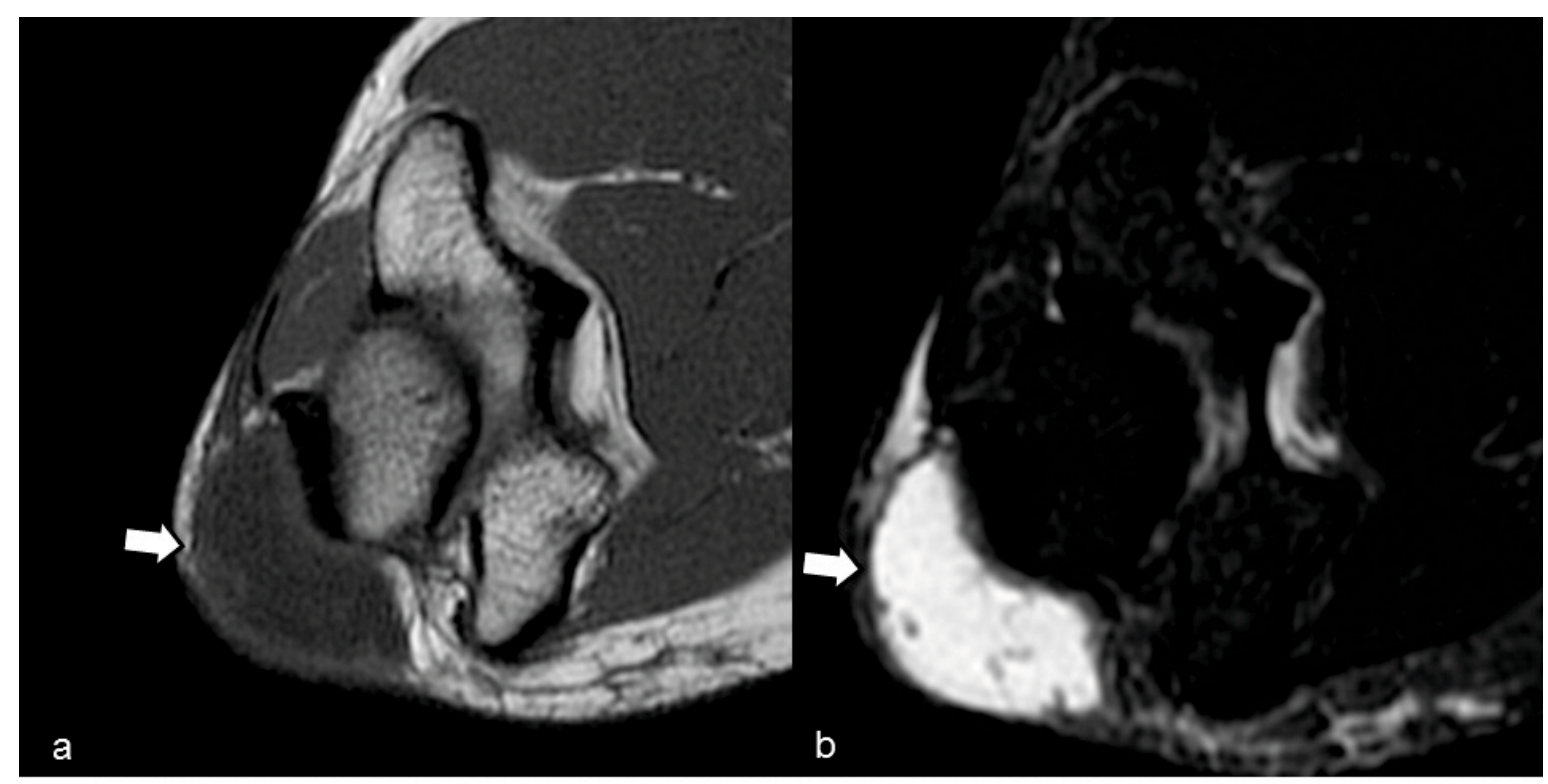

Figure 17 a, b. Bursitis. The axial (a) T1-weighted and the axial (b) STIR MR images show olecranon bursitis (arrows) in a patient that presented with a "mass" in the posterior elbow. 
view of plain radiographs at the time of MRI reporting and correlation with clinical and laboratory findings assists in the correct diagnosis (Figs. 18, 19).

\section{Synovial proliferation disorders}

Various synovial proliferation disorders may be mis- taken as soft tissue tumors and prompt referral for MR imaging ${ }^{1,27,28}$. Lipoma arborescens is a rare intra-articular disorder characterized by villous lipomatous proliferation of the subsynovial tissue and although MR imaging characteristics are not pathognomonic, they are considered strongly suggestive of the

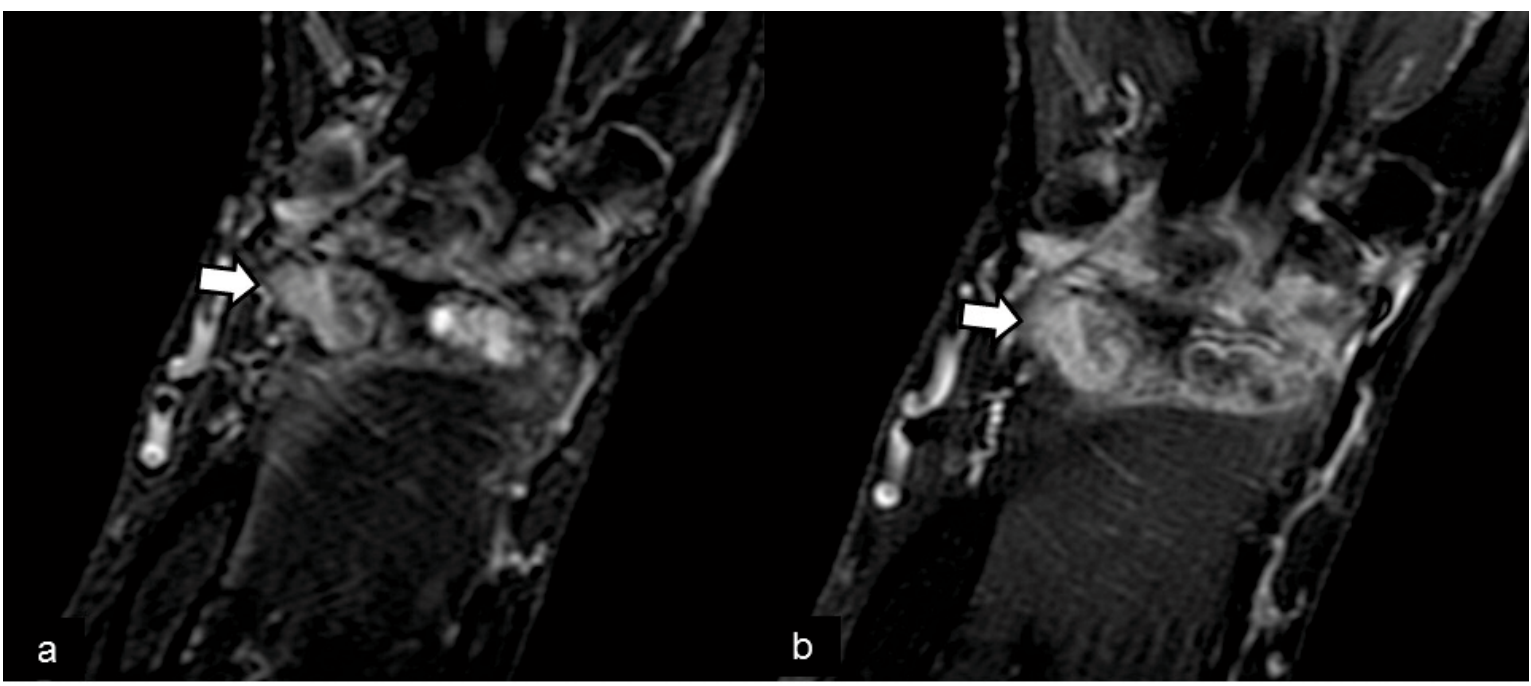

Figure 18 a, b. Rheumatoid arthritis: synovial reaction-pannus formation. The coronal (a) STIR and the coronal (b) contrast enhanced fat saturated T1-weighted MR images demonstrated synovitis (arrows) in a female patient with rheumatoid arthritis of the wrist.

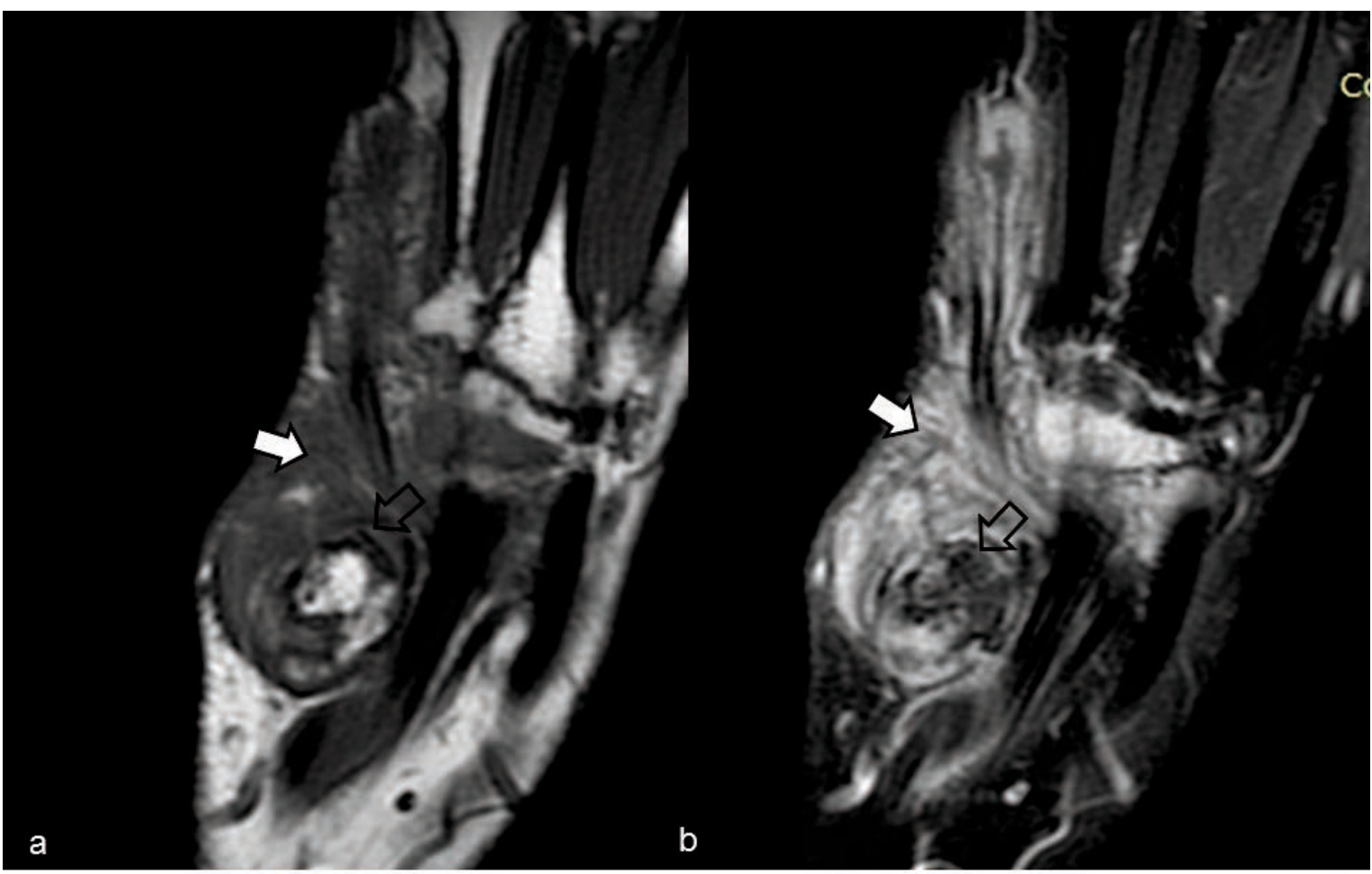

Figure 19 a, b. Gout arthritis: synovial reaction-tophus formation. The coronal (a) T1-weighted and the coronal (b) contrast enhanced fat saturated T1-weighted MR images demonstrated tophus formation (open arrows) and synovitis (arrows) in a male patient with gout arthritis of the wrist. 


\section{E. Perdikakis et al.}

diagnosis 27,28 . MRI can demonstrate the villiform synovial proliferation with signal intensity features similar to that of fat. MR fat saturation sequences and techniques provide the clue to the final diagnosis, together with associated joint effusions usually accompanying MR findings 29 .

Pigmented villonodular synovitis (PVNS) is a rare benign proliferative disorder of the synovium, which may affect joints and bursae in a diffuse or focal form ${ }^{1,27,28}$. On MR imaging, the mass-like proliferative synovium may be interpreted as an aggressive mass. It may demonstrate a lobulated appearance, and it may be extensive in diffuse PVNS or a single nodular lesion in the focal form $1,27,28$. The MR imaging characteristics include low or intermediate signal intensity on T1-weighted images and low signal intensity on T2-weighted and especially gradient-echo images arising from the magnetic susceptibility effect by haemosiderin deposition, since the lesion is prone to repeated bleeding. Giant cell tumours of the tendon sheath (GCTTS) are considered a localized form of PVNS arising from the synovial lining of the tendon sheath. MR imaging typically shows a well-defined nodule or nodular mass adjacent to or encasing a tendon $1,27,28$. The MR imaging characteristics are similar to PVNS, with the prominent low signal intensity on T2-weighted and the "blooming" artifact from haemosiderin deposition (depicted with gradient-echo sequences) being nearly pathognomonic of the diagnosis.

Synovial osteochondromatosis is considered a benign articular disorder of uncertain aetiology and is characterized by synovial proliferation and metaplastic transformation of the synovium with formation of multiple osteocartilaginous nodules ${ }^{27,28}$. The MR imaging findings vary depending on the stage of the disease (early-late), and on the relative proportion of synovial proliferation and degree of calcification of nodules. Correlation with plain radiographs is especially helpful in cases of mature osteocartilaginous-bone nodule formation (Figs. 20-23).

\section{Non-tumoral conditions of the dermis-epidermis that may mimic tumours}

\section{Epidermal inclusion cyst}

Epidermal inclusion cysts (also called epidermal cysts, epidermoid cysts, and infundibular cysts) are the most common type of simple dermal epithelial cystic lesions $^{30}$. They are subcutaneous cysts filled with keratin and cell membrane lipids debris, and lined by a wall of stratified squamous epithelium ${ }^{30}$. They are unilocular cysts without septations, and are encapsulated with a fibrous tissue. T1-weighted and T2-weighted images

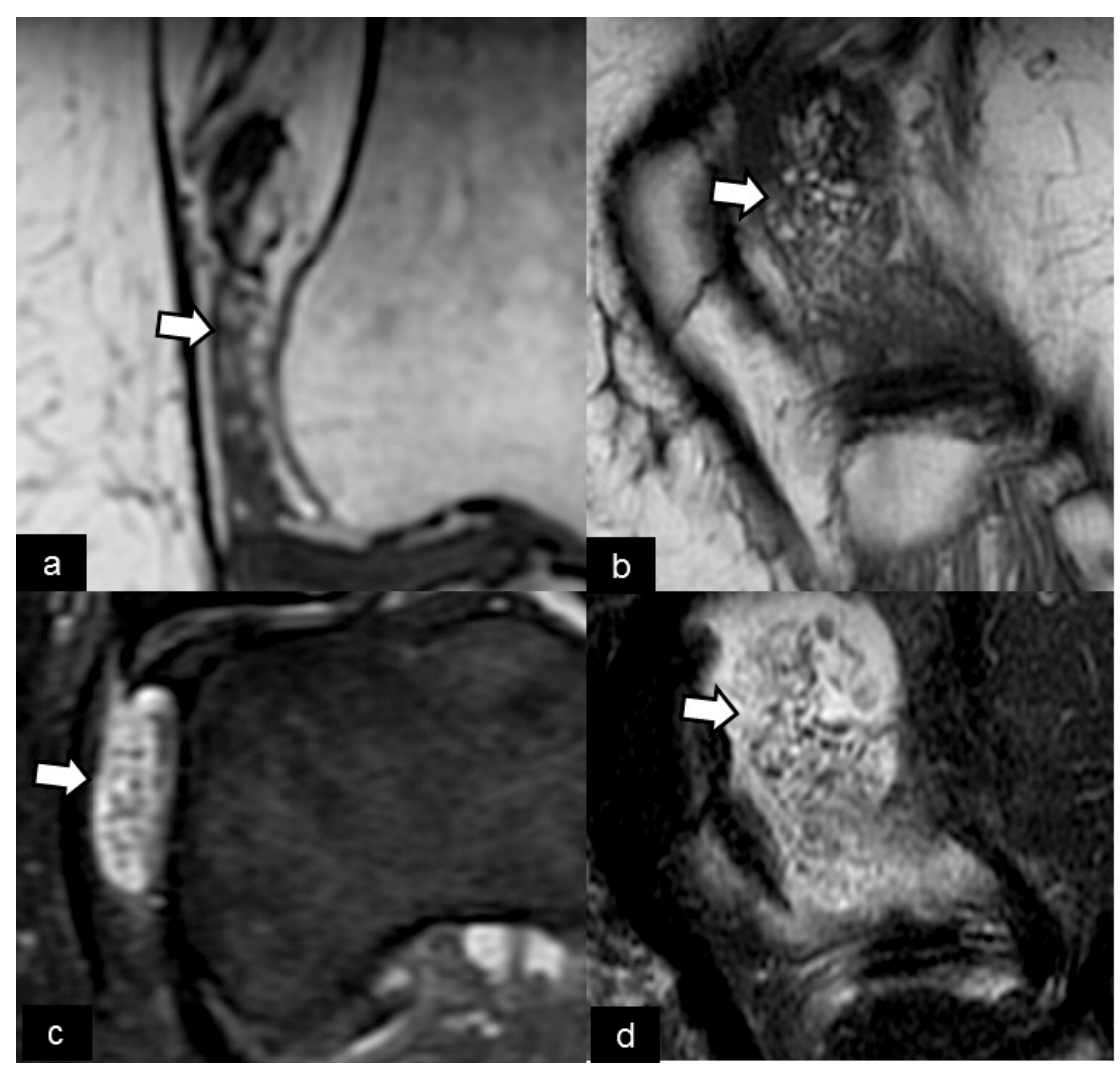

Figure 20 a-d. Lipoma arborescens. The coronal (a) and sagittal (b) T1-weighted and the axial (c) and sagittal (d) PDweighted fat saturated MR images demonstrated "frondlike" fatty proliferation of the synovium (arrows) in the knee joint of a female patient that presented with knee effusion. 


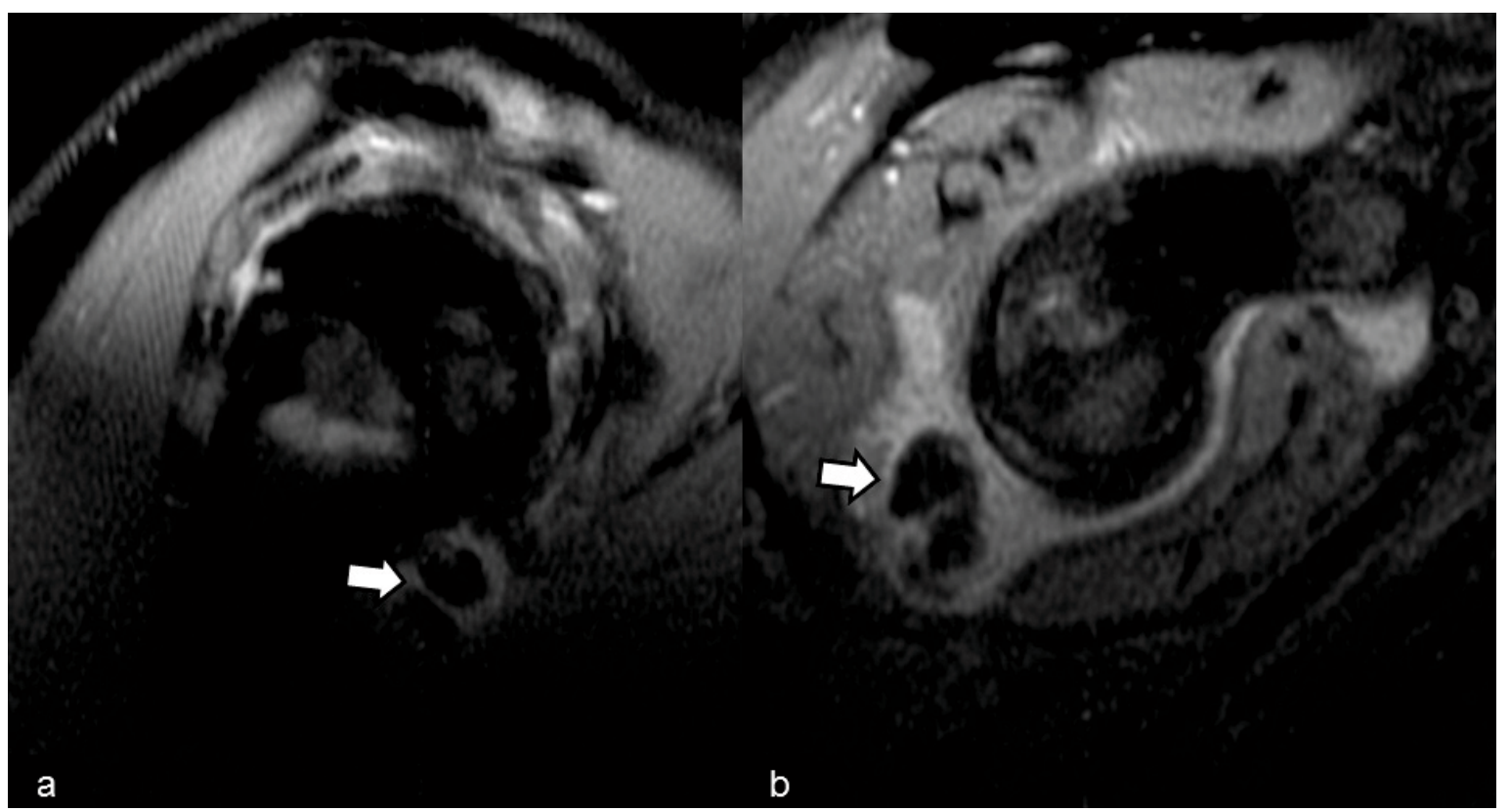

Figure 21 a, b. Synovial osteochondromatosis. The sagittal $(a, b)$ PD-weighted fat saturated MR images demonstrate characteristic findings indicative of synovial metaplasia and proliferation with multiple intra-articular loose bodies (arrows) in the glenohumeral joint of a male patient.

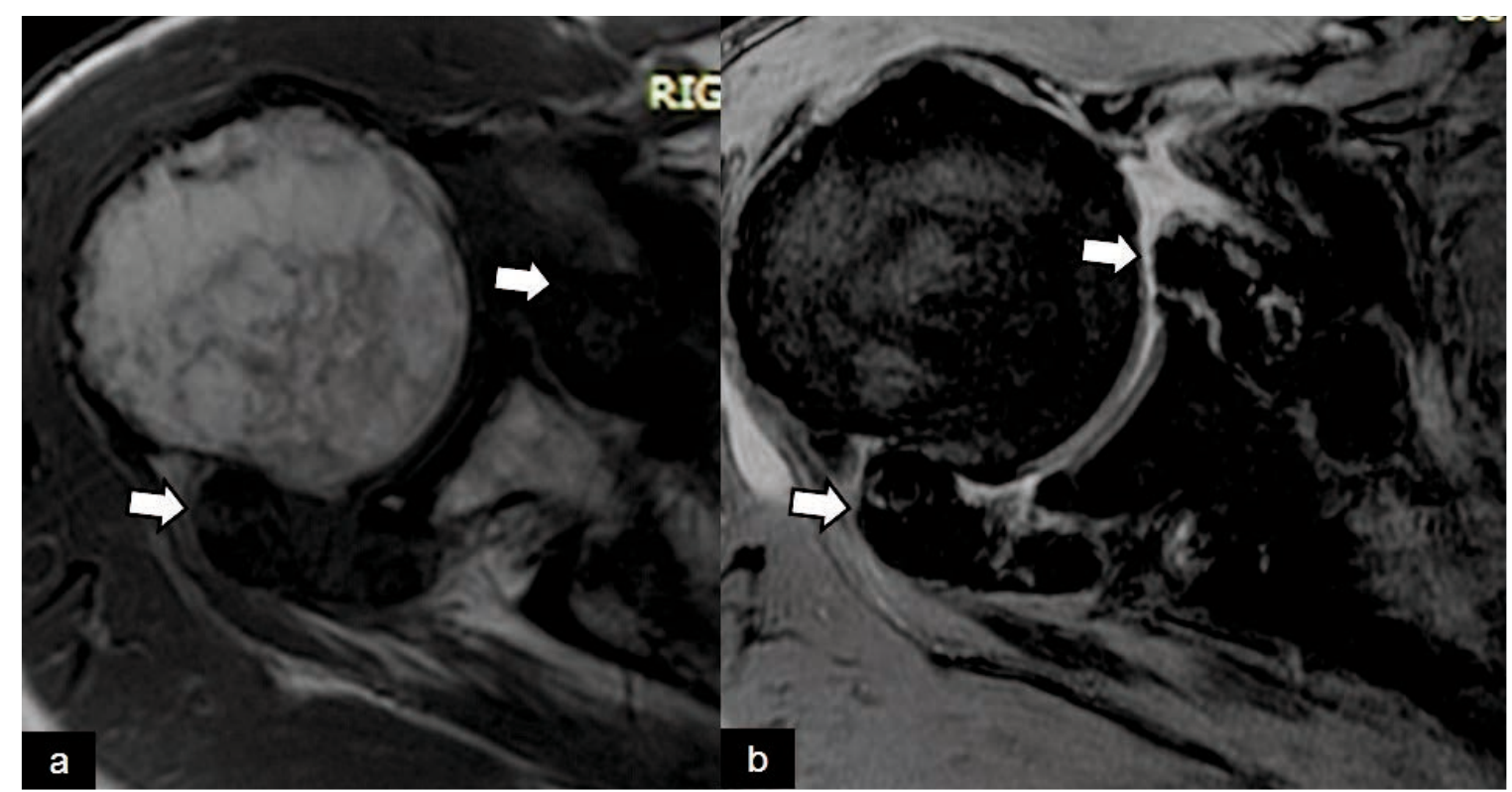

Figure 22 a, b. PVNS: Pigmented villonodular synovitis. The axial (a) T1-weighted and the axial (b) T2-weighted gradient echo MR images demonstrated synovial proliferation with villous and nodular projections and haemosiderin depositions (arrows) in the glenohumeral joint of a female patient.

demonstrate their true cystic component, with peripheral thin rim enhancement after contrast administration. However, when they show variable signal characteristics, complications such as rupture or infection should be suspected. Furthermore, differential diagnosis from other infectious or neoplastic lesions and malignant degeneration of epidermal cysts to squamous cell carcinoma should also be considered (Fig. 24).

\section{Cellulitis-abscess}

Superficial soft tissue infections (dermatitis, cellulitis and superficial abscess formation) are usually diagnosed clinically, and require only antibiotic treatment ${ }^{1,5}$, $8-10$. Imaging is rarely required, but may be necessary when there is clinical suspicion of extension to deep tissues. Ultrasound is usually the first diagnostic test, but MR imaging is considered as the modality of choice for 


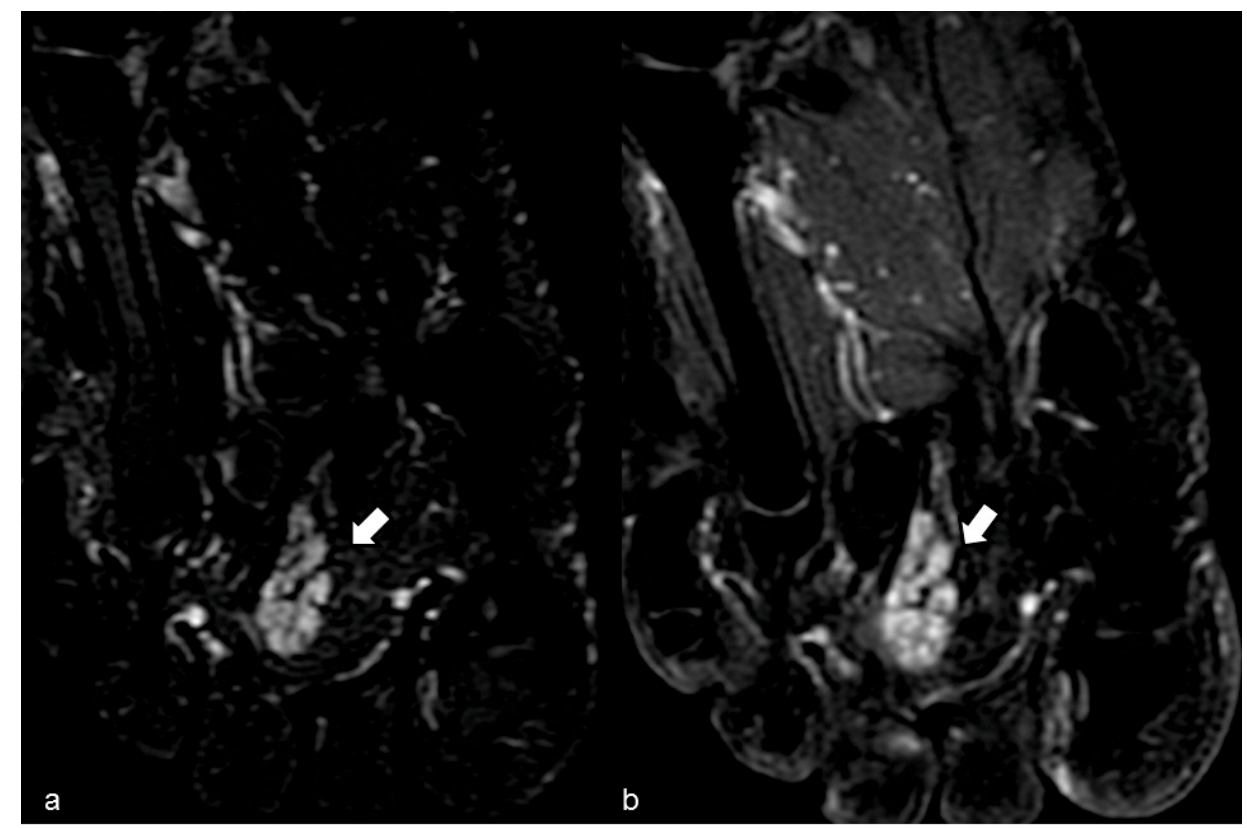

Figure 23 a, b. GCTTS: Giant Cell Tumor of the Tendon Sheath: The coronal (a) STIR and the coronal (b) contrast enhanced fat saturated T1-weighted MR images show a focal enhancing nodular lesion (arrows) emerging from the tendon sheath.

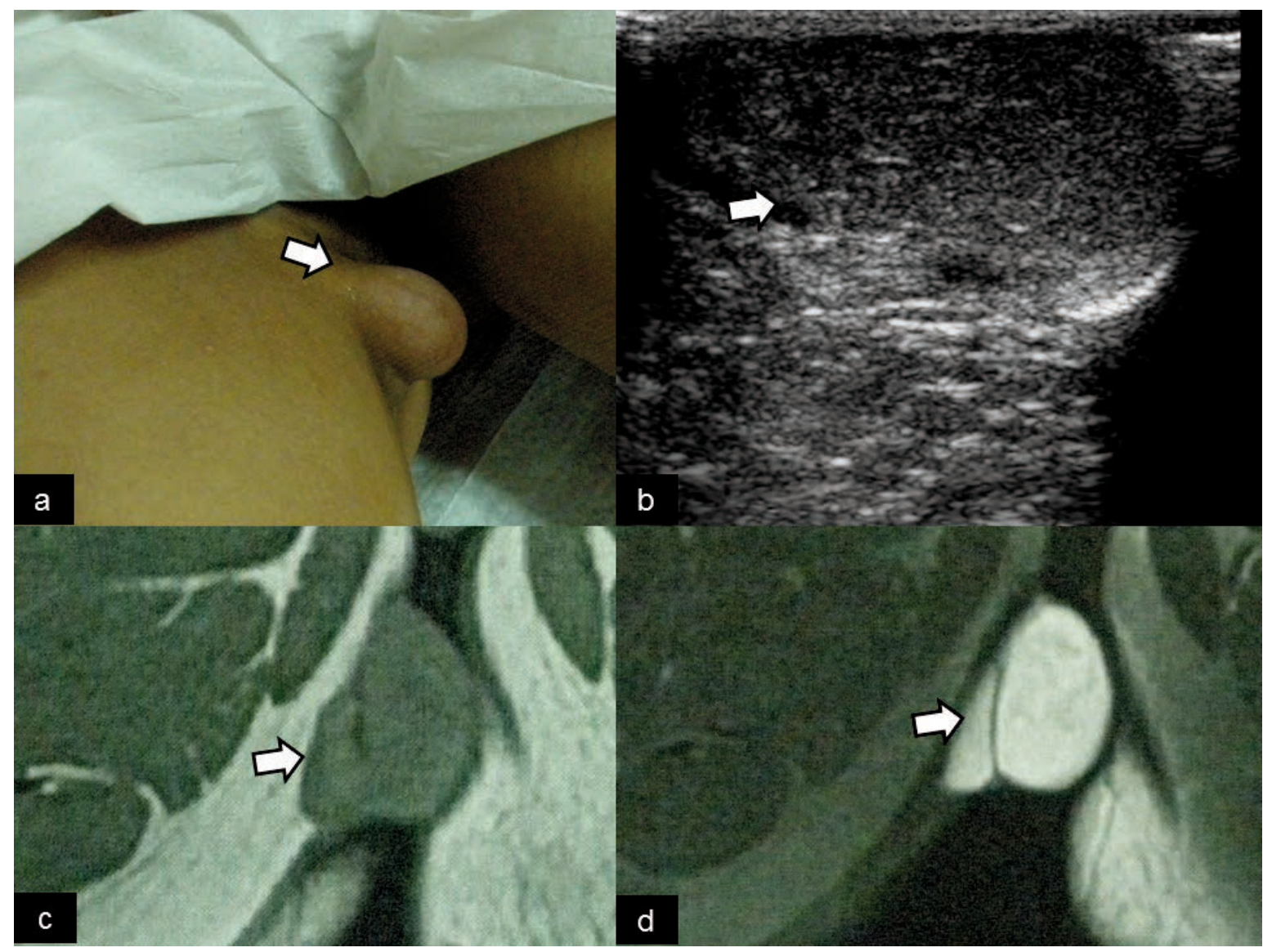

Figure 24 a-d. Epidermal inclusion cyst. The patient presented for evaluation of a pedunculated soft tissue mass (a). The transverse (b) US image and the axial (c) T1-weighted and (d) PD-weighted fat saturated MR images showed the cystic nature of the lesion (arrows) with the presence of internal debris due to keratin debris. 


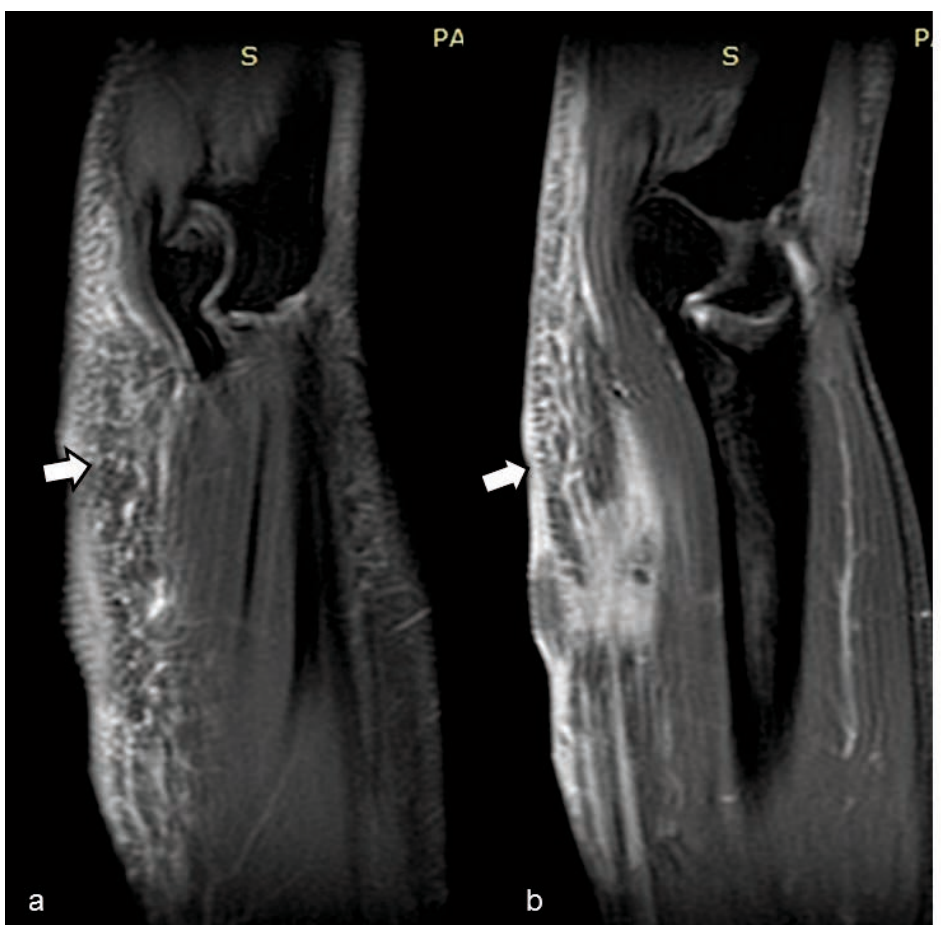

Figure 25 a, b. Cellulitis. The sagittal (a, b) PD-weighted fat saturated MR images show diffuse oedema and thickening of the subcutaneous tissues in a septic patient with skin infection in the elbow area.

providing the best diagnostic approach of musculoskeletal infections ${ }^{1,5,8-10}$. Contrast medium injection usually delineates the site of infection of the superficial soft tissues and provides additional clues in abscess depiction or demonstration of infection extending to deeper compartments. When intravenous gadolinium is contraindicated, the use of fluid-sensitive MR sequences can reliably establish the correct diagnosis and contribute in planning the appropriate treatment (Figs. 25, 26).

\section{Post-traumatic/post-surgical lesions}

Subcutaneous soft tissue changes either of post-traumatic or post-surgical aetiology may cause referral for soft tissue mass evaluation ${ }^{23}$. Fat necrosis after major or minor trauma may result in a palpable mass resulting from organized subcutaneous haematoma formation, fat degeneration and associated fibrosis ${ }^{23}$. Lymphoedema or superficial lymphocele formation may also demonstrate a pseudotumoral appearance ${ }^{23}$. MorelLavallée lesion is a separate post-traumatic entity with distinctive imaging features ${ }^{23}$. The mechanism of trauma includes a closed degloving posttraumatic injury. The subcutaneous fat is separated from the fascia and it manifests as a haemolymphatic mass. The MR imaging characteristics assist in the correct diagnosis by showing the presence of fat globules together with fluid collection, which is commonly located in a perifascial location (Fig. 27).

\section{Non-tumoral conditions of vascular origin that may mimic tumours}

Vascular Malformations-Hemangiomas

Vascular malformations are one of the most common soft tissue pseudotumours and are classified into two main categories: low-flow (lymphatic, capillary, venous, and mixed type) and high-flow (fistula and arteriovenous) vascular anomalies based on their haemodynamic characteristics and histological background ${ }^{31}$. Hemangiomas may manifest as soft-tissue tumors with a cystic-like appearance at MR imaging ${ }^{31}$. They usually demonstrate hypo- or isointense signal on T1-weighted images and hyperintense on T2-weighted images. Signal voids (representing high-flow vessels, phleboliths, or thrombi) may be interspersed with increased signal intensity areas (representing fatty changes). In cases of haemorrhage or thrombosis, heterogeneous signal intensity changes can be depicted on MR images. High proteinaceous content, haemorrhage and fatty deposition may cause increased signal on T1-weighted MR images. Intense enhancement after gadolinium administration is a consequence of the vascular nature of the lesion. In addition, dynamic contrast-enhanced MR angiography provides valuable information about the hemodynamics of vascular soft tissue lesions, helps to differentiate high from low-flow vascular malformations, and aids in planning the treatment strategy regarding these lesions (Fig. 28).

\section{Aneurysms-Pseudoaneurysms}

True arterial wall aneurysms and post-traumatic pseudoaneurysms may mimic soft tissue tumours and present on MR imaging with variable signal intensity changes depending on flow characteristics and pulse sequences applied ${ }^{22,23}$. They are typically related to an arterial vessel, and the lesion shows continuity with the artery, a finding which leads to the correct diagnosis. In chronic cases, a laminated MR appearance is consistent with multilayered thrombus; occasionally, rim-like 


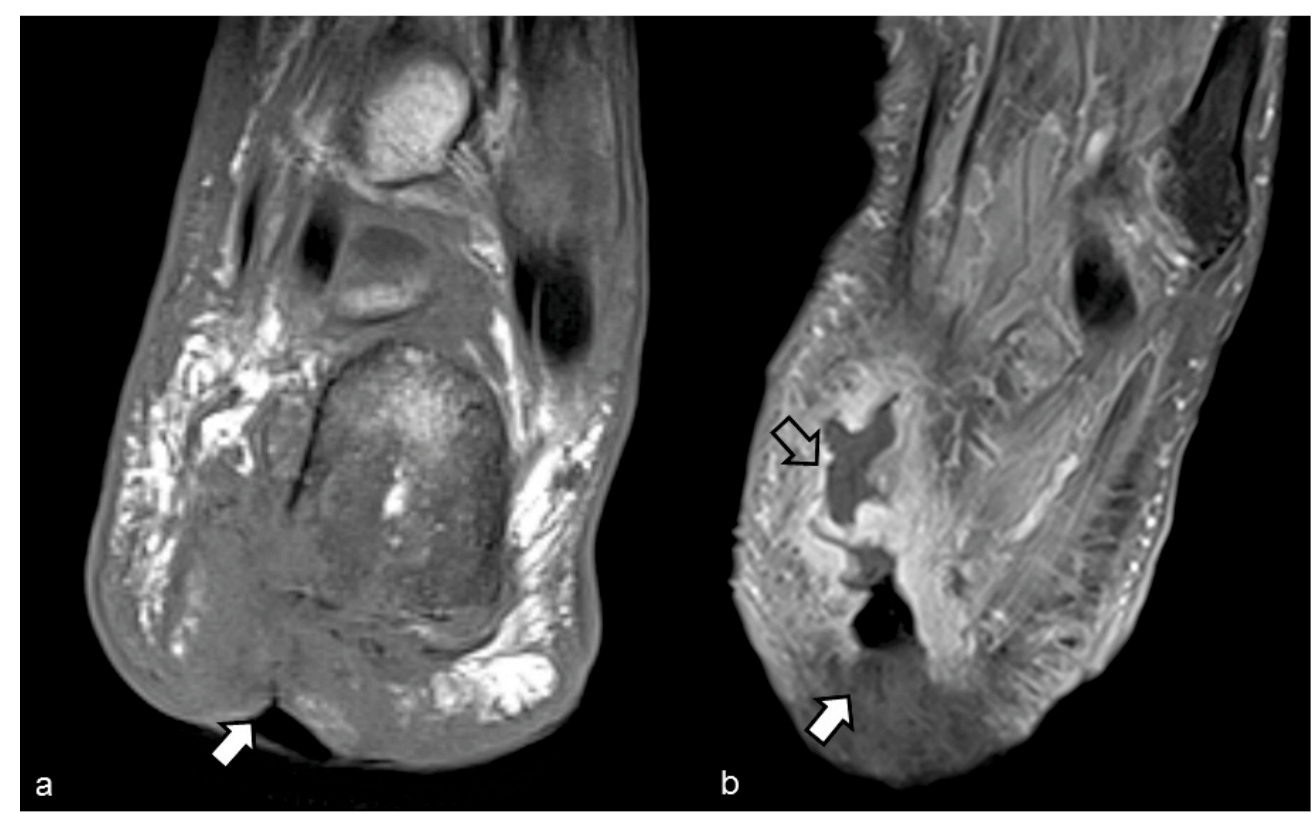

Figure 26 a, b. Cellulitis-Abscess. The coronal (a) T1-weighted and the axial (b) contrast enhanced fat saturated T1-weighted MR images show cellulitis and skin ulceration (arrows) and a small abscess (open arrow) in the subcutaneous calcaneal tissues of a diabetic patient with calcaneal osteomyelitis.

calcifications may also be depicted and may complicate MR interpretation. In such cases, the blood flow pro-

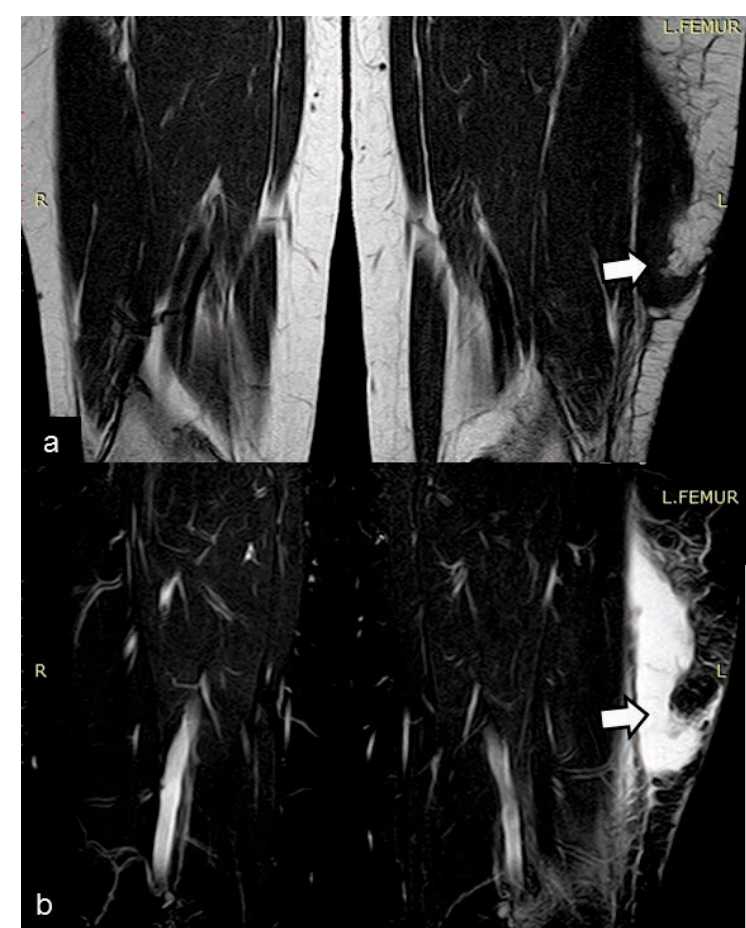

Figure 27 a, b. Post-traumatic: Morel-Lavallée lesion. The coronal (a) T1-weighted and the coronal (b) STIR MR images demonstrated that the" palpable lesion" in this patient corresponded to skin and subcutis separated from the fascia, producing a cavity that was filled with fluid and debris. Clinical history revealed a bike accident. duces a characteristic artifact that is a hallmark in the diagnosis 22, 23 (Fig. 29).

\section{Varices}

Varices are focal dilatations of an incompetent vein 22 , 23. They are usually seen in the lower limb, and may simulate a soft tissue mass especially if they are complicated with thrombosis. On MR images they are seen as lobulated masses in continuity with the vein, which aids in the correct diagnosis (Fig. 30).

\section{Non-tumoral conditions of neural origin that may mimic tumours}

\section{Morton's neuroma}

Morton's neuroma is a benign non-neoplastic lesion that is attributed to perineural fibrosis and degeneration around the plantar digital nerve $2,3,27$. Most lesions occur in the second or third intermetatarsal interspace. There is a high predominance of symptomatic lesions in female population, but the lesion is very common in asymptomatic patients, and can be detected on MR imaging as an incidental finding 2 , 3, 27. On MR imaging, a Morton's neuroma classically appears as a teardropshaped mass in the intermetatarsal space. The mass is usually isointense to muscle on T1-weighted images, and hypointense to fat on T2-weighted images. Lesions can show variable enhancement after gadolinium administration, and contrast enhanced MRI is usually suggested in patients with characteristic forefoot pain and high suspicion of Morton's neuroma, to better depict the lesion (Fig. 31).

Perineural cyst

Perineural cysts are dilatations (typically seen as CSF 


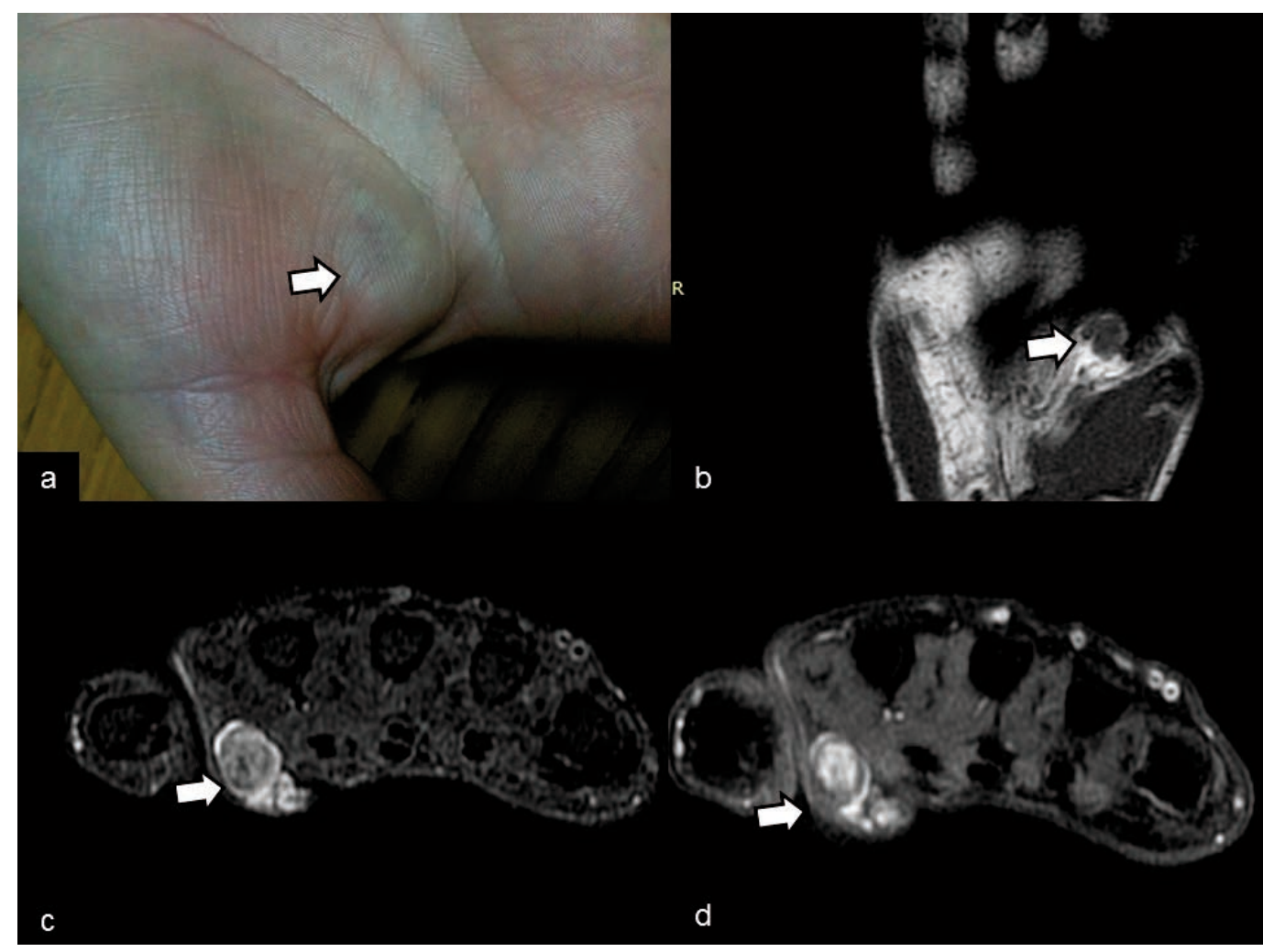

Figure 28 a-d. Vascular malformation-Hemangioma. The patient presented with a soft tissue mass with slight skin discoloration (arrow in a). The coronal (b) T1-weighted and the axial (c) T2-weighted MR images verified the presence of the small mass that showed evidence of internal haemorrhage and fibrosis. The axial (d) contrast enhanced fat saturated T1weighted MR image demonstrated the feeding vessels of this hemangioma.

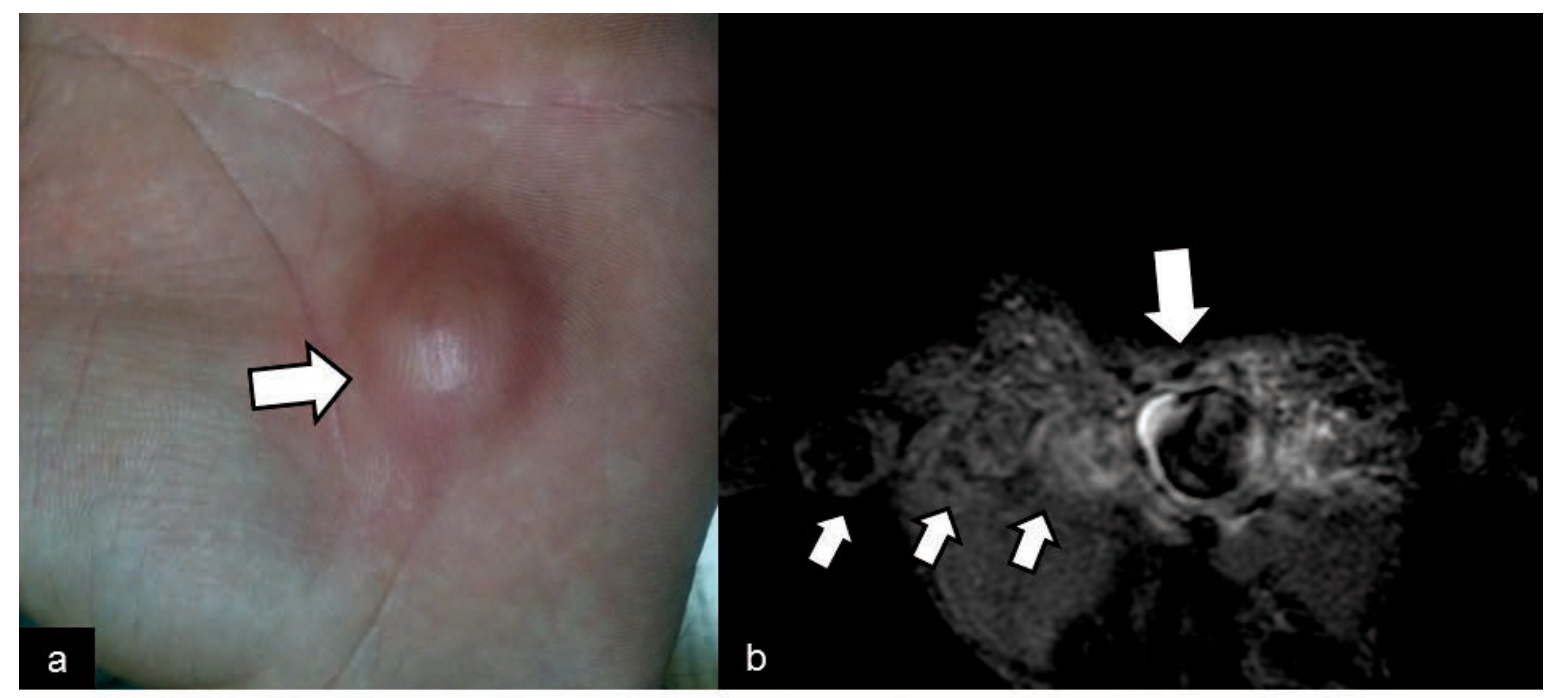

Figure 29 a, b. Pseudoaneurysm. The patient presented with a slowly enlarging mass (a) of the hand. The coronal (b) STIR MR image shows the presence of a pseudoaneurysm (large arrow) with internal thrombus (please also note vessel wall motion artifact-small arrows in b). Clinical history revealed a recent occupational accident with an electric drill that penetrated his hand in the affected area.

filled near the spine) of the nerve sheath, and are usually incidental MR findings ${ }^{1-3,5}, 22,23,27$. Although the aetiology of perineural cysts is unclear, theories have attributed its cause to congenital, post-traumatic, and post-inflammatory factors ${ }^{1-3}, 5,22,23,27$. Even though asymptomatic, in some patients it appears that per- 


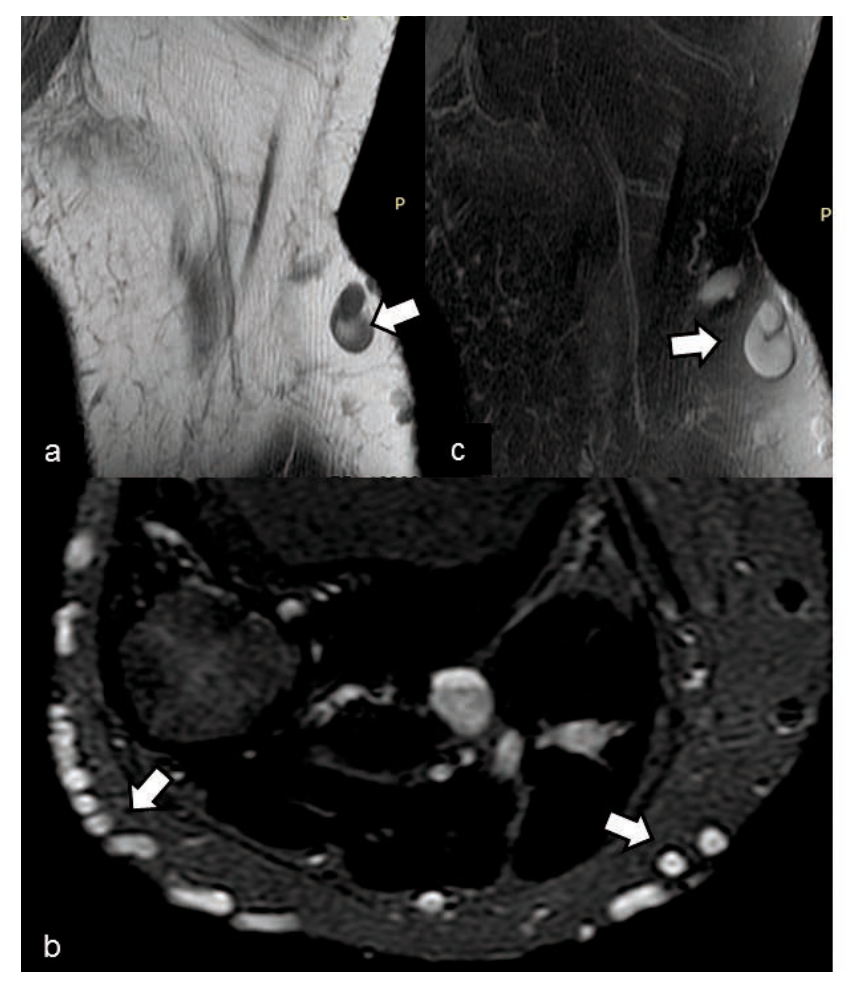

Figure 30 a-c. Varices. The sagittal (a) T1-weighted and the axial (b) and sagittal (c) PD-weighted fat saturated MR images show multiple subcutaneous varices (arrows) in this female patient.

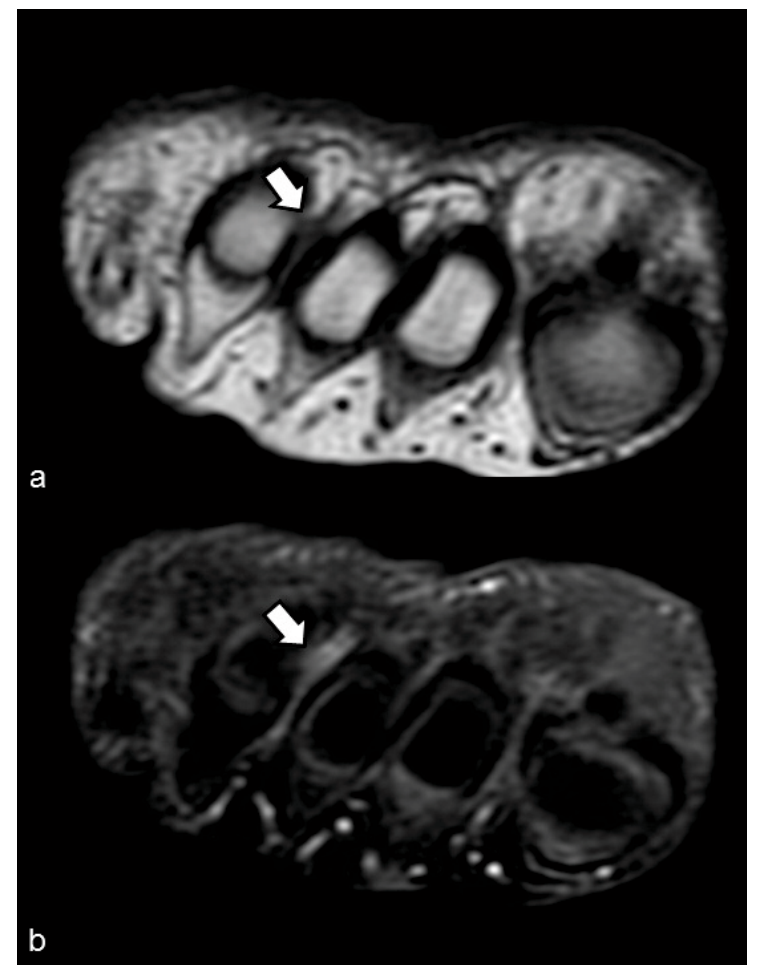

Figure 31 a, b. Morton's neuroma. The axial (a) T1-weighted and the axial (b) contrast enhanced fat saturated T1weighted MR images demonstrate that in the 3rd-4th intermetatarsal space there is focal perineural thickening-enlargement and enhancement of the interdigitalis nerve (arrows), findings in keeping with the diagnosis of Morton's neuroma. ineural cysts may cause neural related pain and discomfort, and large cysts may cause local pressure effects and result in muscle denervation of the affected nerve. MRI is considered the modality of choice for demonstrating both the perineural cyst as well as possible related denervation findings ${ }^{1-3,5}, 22,23,27$ (Fig. 32).

\section{Miscellaneous non-tumoral conditions}

\section{Lymph nodes}

In general, benign forms of regional lymphadenitis may demonstrate clinical and imaging findings that may be interpreted as soft tissue tumour ${ }^{22,23}$. Identification of the normal MR appearance of the lymph node fatty hilum aids in the differential diagnosis. Correlation of imaging findings with clinical and laboratory examinations is also imperative (Fig. 33).

\section{Tumoral calcinosis}

Tumoral calcinosis is rare, and is classified as primary (idiopathic or hereditary) or secondary ${ }^{5}$. It is characterized by the formation of soft-tissue calcified lesions most commonly around the extensor surface of large joints ${ }^{5}$. The most common locations of tumoral calcinosis are the hip, elbow, shoulder, foot, and wrist. The imaging findings may mimic a more aggressive lesion and interpretation of all radiologic examinations may thus be needed in achieving a correct diagnosis. At CT, the lobulated cystic calcifications are depicted, and communication with the joint bursa in the majority of the cases is seen. On T1-weighted MR images, the calcified lesions may show inhomogeneous low signal intensity and on T2-weighted MR imaging a diffuse low-sig- 


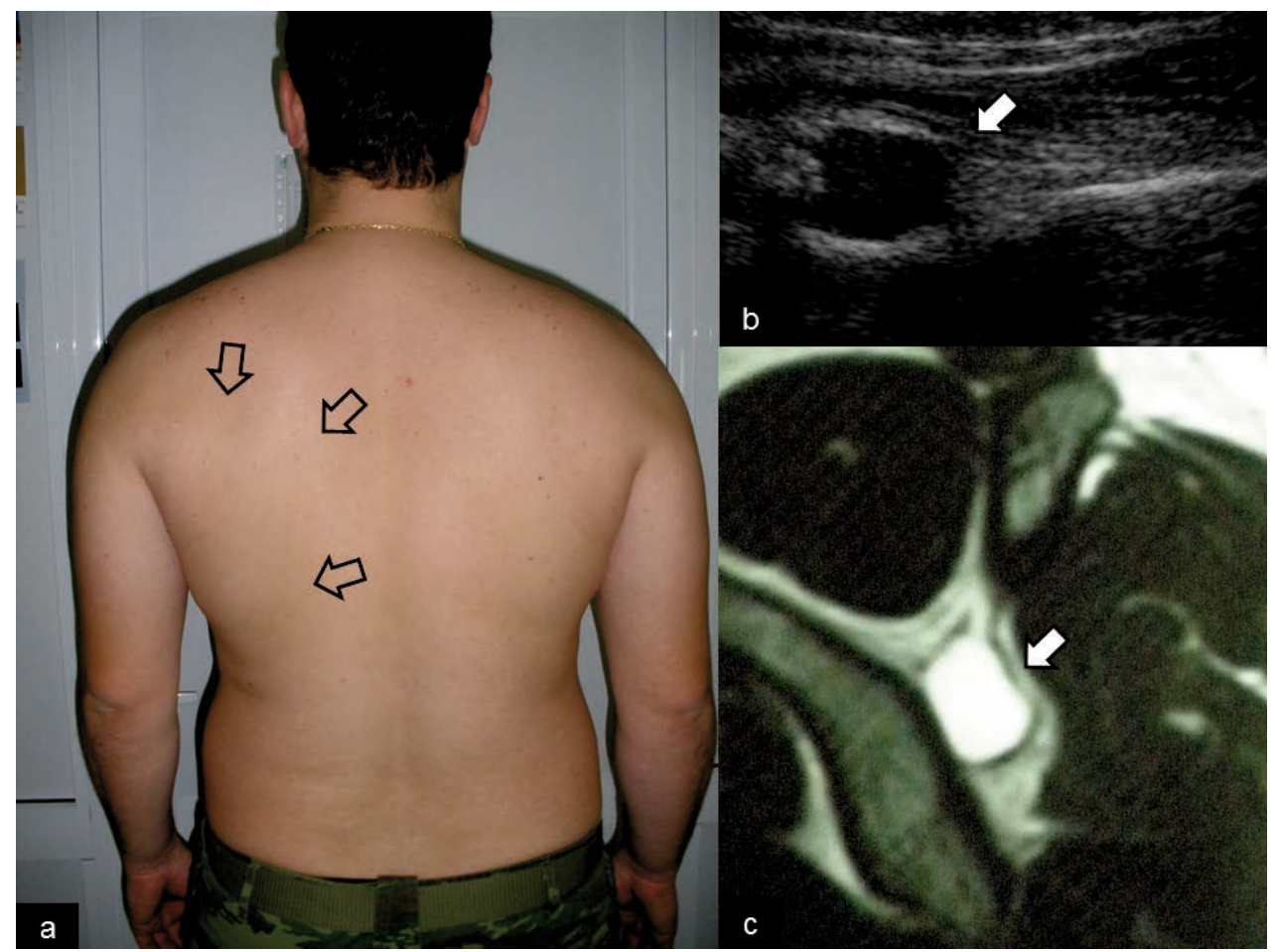

Figure 32 a-c. Perineural cyst. The patient presented with infraspinatus muscle atrophy (arrows in a). The longitudinal (b) ultrasound and the sagittal (c) T2-weighted MR images demonstrated a small cyst (arrows) in the suprascapular notch that was proven surgically as a nerve sheath cyst of a suprascapular nerve division branch.

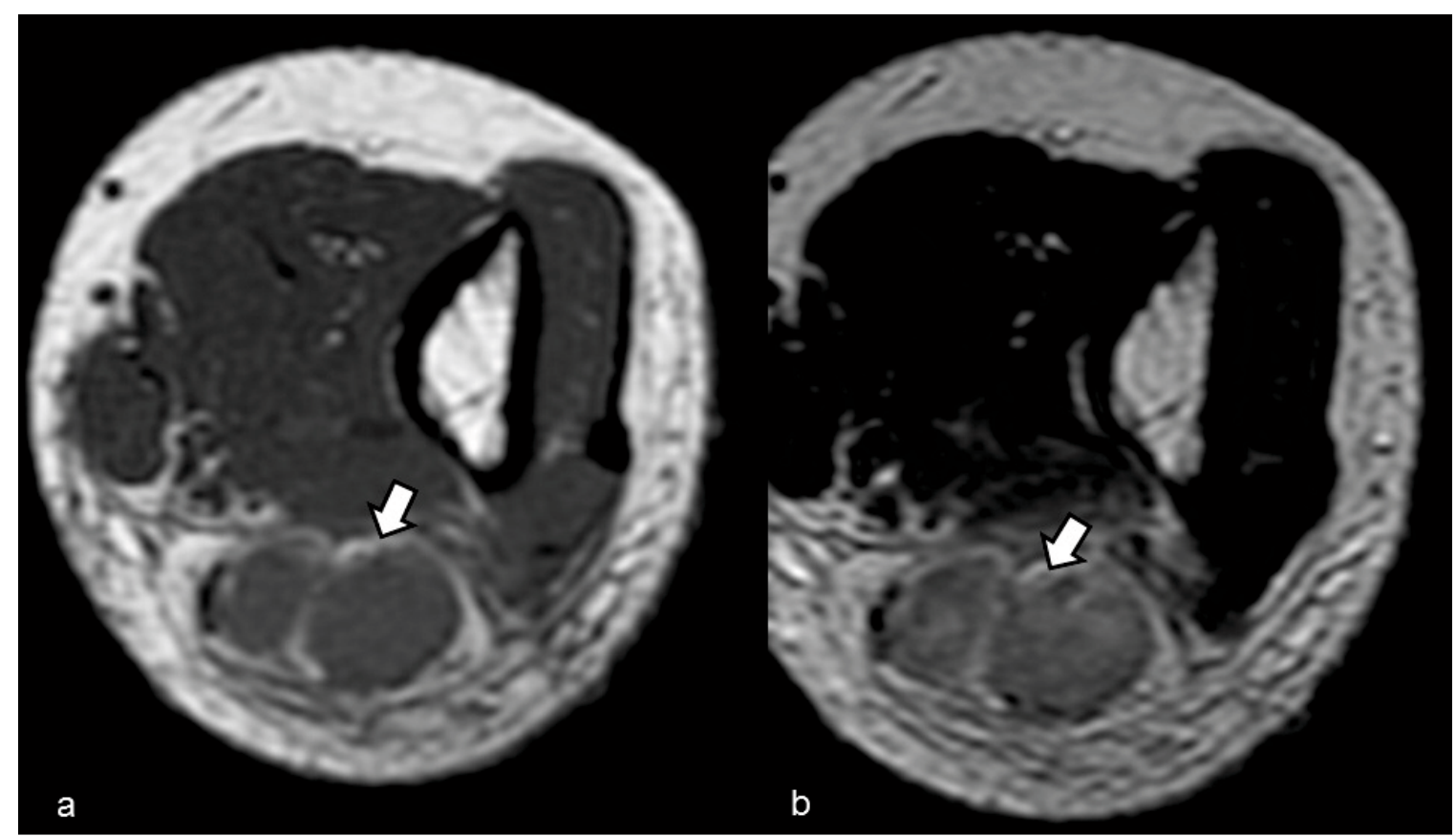

Figure 33 a, b. Cat scratch disease. The axial (a) T1-weighted and the axial (b) T2-weighted MR images show multiple subcutaneous lymph nodes (arrows) that was proven serologically as Bartonella Henselae infection. The patient reported recent contact with cats.

nal-intensity pattern or a high signal intensity pattern may be noted (Fig. 34).
Foreign body reaction (granuloma/abscess)

Foreign body-induced soft-tissue masses are most of- 


\section{E. Perdikakis et al.}

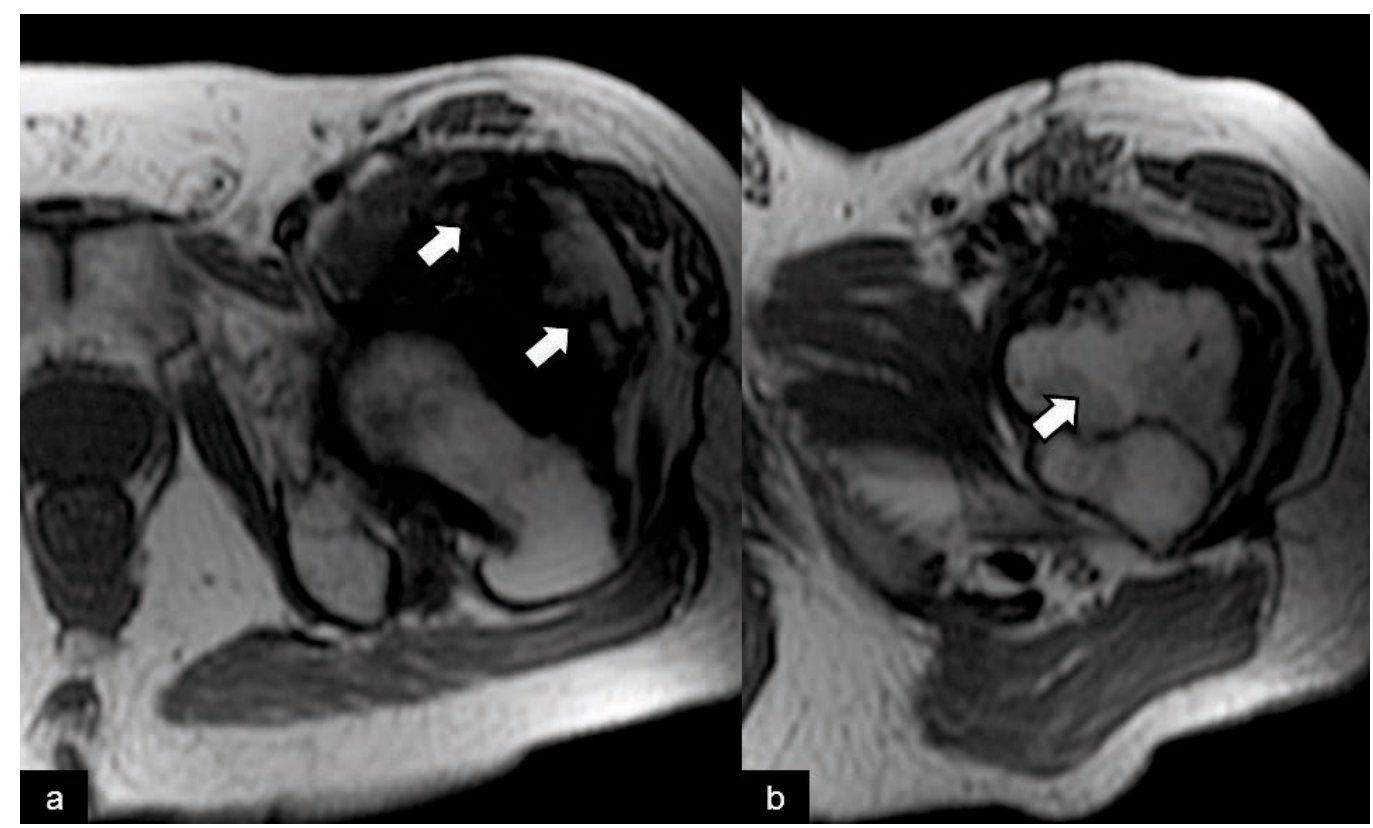

Figure 34 a, b. Tumoral calcinosis. The axial (a, b) T1-weighted MR images show massive periarticular calcinosis of the soft tissues (arrows) in a patient with tumoral calcinosis.

ten found adjacent to the area of trauma and skin laceration $^{1-3,5}, 9$. Some patients may not recall the traumatic incident. The subcutaneous fat layer may demonstrate a variety of signal intensity changes that correspond to the stages of inflammation and/or infection-abscess formation $1-3,5,9$. Accurate patient history and direct visual examination of the lesion may narrow the differential diagnosis. Radiographs, ultrasound, CT and MRI may help to identify the foreign object depending on its origin (wood, glass, rock, etc.) (Fig. 35).

\section{Conclusion}

A wide range of soft tissue pseudotumours may be encountered in clinical practice or when patients undergo radiologic examinations. MRI can be particularly useful to characterize benign lesions that do not require imaging follow-up or biopsy. When a soft-tissue lesion is indeterminate on the basis of clinical and imaging features, a biopsy should be considered.

Finally, this research has been conducted according to

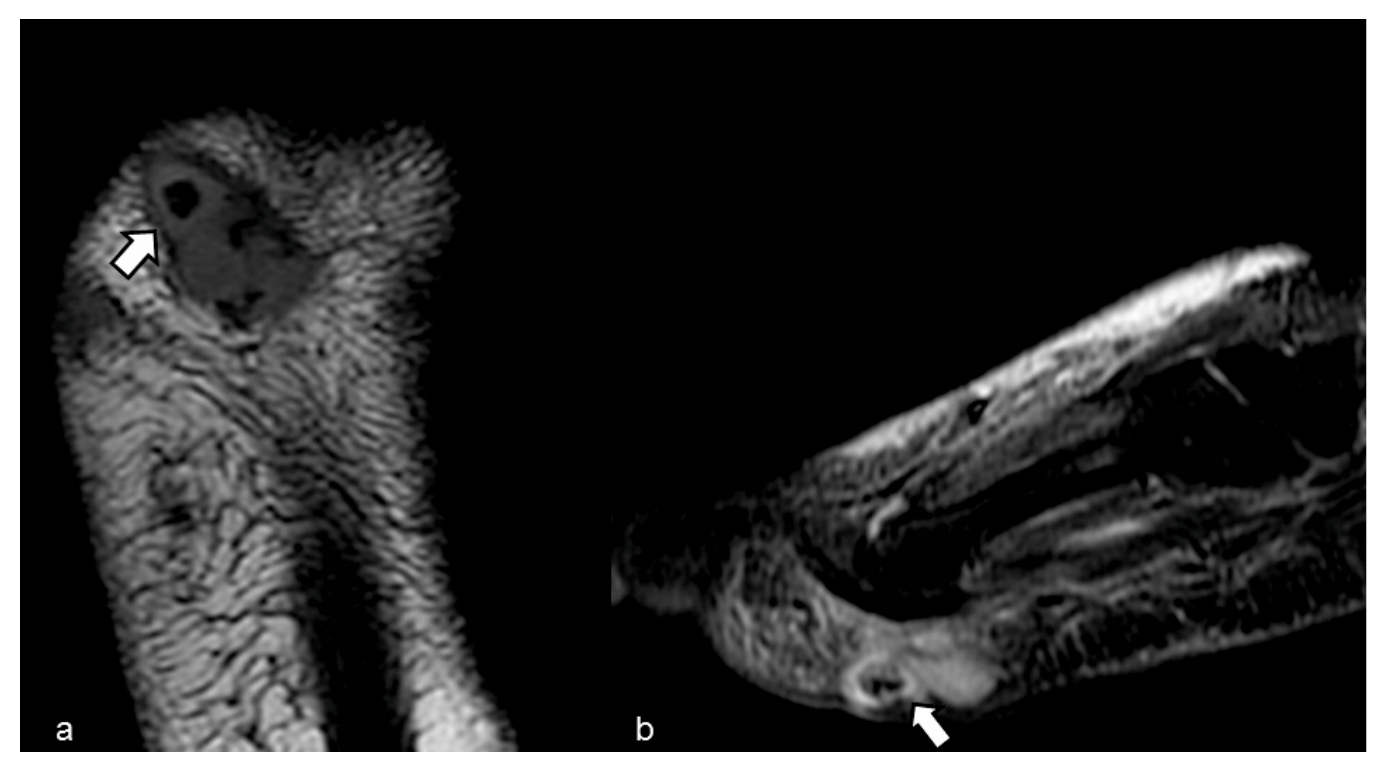

Figure 35 a, b. Foreign body reaction. The axial (a) T1-weighted and the sagittal (b) STIR MR images show focal inflammatory changes with pus formation in a patient with history of being injured by a wood splinter (arrows). 
the international ethical and scientific standards and as required by the Journal ${ }^{32}$.

\section{Conflict of interests}

The Authors declare that they have no conflict of interests regarding the publication of this paper.

\section{References}

1. Vanhoenacker FM, Eyselbergs M, Van Hul E, Van Dyck P, De Schepper AM. Pseudotumoural soft tissue lesions of the hand and wrist: a pictorial review. Insights Imaging. 2011;2:319-333

2. Hung EH, Griffith JF. Pitfalls in ultrasonography of soft tissue tumors. Semin Musculoskelet Radiol. 2014;18:79-85.

3. Wu JS, Hochman MG. Soft-tissue tumors and tumorlike lesions: a systematic imaging approach. Radiology. 2009;253: 297-316

4. Hayashi D, Hamilton B, Guermazi A, de Villiers R, Crema MD, Roemer FW. Traumatic injuries of thigh and calf muscles in athletes: role and clinical relevance of MR imaging and ultrasound. Insights Imaging. 2012;3:591-601.

5. Arkun R, Argin M. Pitfalls in MR imaging of musculoskeletal tumors. Semin Musculoskelet Radiol. 2014;18:63-78.

6. Counsel P, BreidahI W. Muscle injuries of the lower leg. Semin Musculoskelet Radiol. 2010;14:162-175.

7. Yammine K. The accessory peroneal (fibular) muscles: peroneus quartus and peroneus digitiquinti. A systematic review and meta-analysis. Surg Radiol Anat. 2015;37:617-627.

8. Booth TC, Chhaya NC, Bell JR, Holloway BJ. Update on imaging of non-infectious musculoskeletal complications of HIV infection. Skeletal Radiol. 2012;41:1349-1363.

9. Turecki MB, Taljanovic MS, Stubbs AY, et al. Imaging of musculoskeletal soft tissue infections. Skeletal Radiol. 2010;39: 957-971.

10. Chaudhry AA, Baker KS, Gould ES, Gupta R. Necrotizing fasciitis and its mimics: what radiologists need to know. AJR Am J Roentgenol. 2015;204:128-139.

11. Khan W, Zoga AC, Meyers WC. Magnetic resonance imaging of athletic pubalgia and the sports hernia: current understanding and practice. Magn Reson Imaging Clin N Am. 2013;21: 97-110.

12. Campbell R. Ultrasound of the athletic groin. Semin Musculoskelet Radiol. 2013;17:34-42.

13. Dönmez G, Evrenos MK, Cereb M, Karanfil Y, Doral MN. Double layer repair of tibialis anterior muscle hernia in a soccer player: a case report and review of the literature. Muscles Ligaments Tendons J. 2016;5:331-334.

14. Pesquer L, Poussange N, Sonnery-Cottet B, et al. Imaging of rectus femoris proximal tendinopathies. Skeletal Radiol. 2016;45:889-897.

15. Sivasundaram L, Matcuk GR Jr, White EA, Hatch GF 3rd, Pa- tel DB. Partial semitendinosus tendon tear in a young athlete: a case report and review of the distal semitendinosus anatomy. Skeletal Radiol. 2015;44:1051-1056.

16. Malliaropoulos NG. Non contact hamstring injuries in sports. Muscles Ligaments Tendons J. 2013;2:309-311.

17. Merrow AC, Reiter MP, Zbojniewicz AM, Laor T. Avulsion fractures of the pediatric knee. Pediatr Radiol. 2014;44:14361445.

18. Lempainen L, Johansson $\mathrm{K}$, Banke IJ, et al. Expert opinion: diagnosis and treatment of proximal hamstring tendinopathy. Muscles Ligaments Tendons J. 2015;5:23-28.

19. Weinreb JH, Sheth $\mathrm{C}$, Apostolakos J, et al. Tendon structure, disease, and imaging. Muscles Ligaments Tendons J. 2014;4:66-73.

20. Patel DB, Emmanuel NB, Stevanovic MV, et al. Hand infections: anatomy, types and spread of infection, imaging findings, and treatment options. Radiographics. 2014;34:19681986.

21. Luong DH, Smith J, Bianchi S. Flexor carpi radialis tendon ultrasound pictorial essay. Skeletal Radiol. 2014;43:745-760.

22. Perdikakis E, Skiadas V. MRI characteristics of cysts and "cyst-like" lesions in and around the knee: what the radiologist needs to know. Insights Imaging. 2013;4:257-272.

23. Bermejo A, De Bustamante TD, Martinez A, Carrera R, Zabía $E$, Manjón P. MR imaging in the evaluation of cystic-appearing soft-tissue masses of the extremities. Radiographics. 2013;33:833-855.

24. Puig S, Kuruvilla YC, Ebner L, Endel G. Magnetic resonance tomography of the knee joint. Skeletal Radiol. 2015;44:14271434.

25. Bancroft LW. Wrist injuries: a comparison between high- and low-impact sports. Radiol Clin North Am. 2013;51:299-311.

26. McNally EG, Shetty S. Plantar fascia: imaging diagnosis and guided treatment. Semin Musculoskelet Radiol. 2010;14:334343.

27. Stacy GS, Dixon LB. Pitfalls in MR image interpretation prompting referrals to an orthopedic oncology clinic. Radiographics. 2007;27:805-826.

28. Sheldon PJ, Forrester DM, Learch TJ. Imaging of intraarticular masses. Radiographics. 2005;25:105-119.

29. Tsifountoudis I, Kapoutsis D, Tzavellas AN, Kalaitzoglou I, Tsikes A, Gkouvas G. Lipoma arborescens of the knee: report of three cases and review of the literature. Case Rep Med. 2017;2017:3569512.

30. Beaman FD, Kransdorf MJ, Andrews TR, Murphey MD, Arcara LK, Keeling JH. Superficial soft-tissue masses: analysis, diagnosis, and differential considerations. Radiographics. 2007:27:509-523.

31. Flors L, Leiva-Salinas C, Maged IM, et al. MR imaging of softtissue vascular malformations: diagnosis, classification, and therapy follow-up. Radiographics. 2011;31:1321-1340.

32. Padulo J, Oliva F, Frizziero A, Maffulli N. Muscles, Ligaments and Tendons Journal - Basic principles and recommendations in clinical and field science research: 2016 update. MLTJ. 2016;6(1):1-5. 